Bull. Mater. Sci., Vol, 6, No. 5, September 1984, pp. 923-958. C) Printed in India.

\title{
Plutonium metallurgy in India
}

\author{
P R ROY and C GANGULY \\ Radiometaliurgy Division, Bhabha Atomic Research Centre, Bombay 400085, India
}

\begin{abstract}
The embryo of plutonium metallurgy in India, as well as in Asia, was formed nearly 25 years back in Trombay. Thereafter, in the intervening 25 years, significant amount of research and development work have been carried out at BARC on this man-made fissile element and indigenisation has been achieved in the fabrication, characterisation and property evaluation of plutonium metal, delta-stabilised alloys, Al-Pu fuels, Pu-Be neutron sources, (UPu) $\mathrm{O}_{2}$ fuels for thermal and fast reactors and (UPu)C and (UPu)N advanced fuels for liquid metal-cooled fast breeder reactors (LMFBR).

This paper summarises the development of plutonium metallurgy in India highlighting the safety aspects, our achievements and potential of plutonium for generation of nuclear electricity in the coming decades.
\end{abstract}

Keywords. Plutonium; fissile; delta-stabilised alloys; Al-Pu fuels; Pu-Be neutron sources; Mixed oxide and carbide fuels; fast breeder-test reactor; liquid metal-cooled fast breeder reactors; nuclear electricity.

\section{Introduction}

The metallurgy of plutonium, the man-made unique and most unusual metal, was introduced in India in 1960 when a team consisting of a chemist, a chemical engineer and a metallurgist successfully isolated mg quantities of plutonium metal beads in the Trombay laboratory by calciothermic reduction of plutonium tetrafluoride. Thereafter, in the intervening 25 years, there has been an enormous scale-up of production and extensive investigation of plutonium metal, its alloys and compounds. A sophisticated plutonium metallurgy laboratory for safe and secured fabrication and characterisation of plutonium fuels has come up in Trombay and today we are on the threshold of intensive utilisation of plutonium for generation of nuclear electricity and breeding of fissile materials simultaneously.

Plutonium does not occur in nature but is synthetically formed by the transmutation of the naturally occurring ${ }_{92}^{238} \mathrm{U}$. Soon after its discovery by Seaborg, Wahl and Kennedy in February 1941, in the Berkeley laboratory in USA, plutonium served as a major ingredient of the Manhattan nuclear weapon project during the second world war (Seaborg 1958). However, today it is most significant because of its peaceful potential as a nuclear reactor fuel offering energy thousand times greater than all available fossil fuels.

From the very inception of nuclear energy programme in India in the mid 1950s, the tremendous potential of plutonium for unlocking the huge energy reserves of our limited uranium (Rao 1982) ( $\sim 60000$ tons) and abundant thorium ( $~ 320000$ tons) resources was recognised. Accordingly, laboratory separation and analytical procedures for plutonium started in Trombay in 1958 and by 1964 our spent uranium fuel reprocessing plant for recovery of plutonium was commissioned, for the first time in Asia. 
The present dissertation summarises the milestones of plutonium metallurgy in India, highlighting our achievements in development and fabrication of plutonium metal and plutonium bearing metallic and ceramic fuels and our future programme for utilisation of plutonium for generation of nuclear electricity.

\section{Formation and separation}

As is known, uranium occurring in nature contains mainly two isotopes, viz. ${ }^{238} \mathrm{U}$ $(99.3 \%)$ and ${ }^{235} \mathrm{U}(0.7 \%)$. The present generation of nuclear reactors derive energy from the fission of ${ }^{235} \mathrm{U}$ by slow or thermal neutrons and use natural uranium or 2 to $4 \%{ }^{235} \mathrm{U}$ enriched uranium in the form of metal or oxide as fuels. The fission reaction is as follows:

$$
{ }_{92}^{235} \mathrm{U}+{ }_{0}^{1} \mathrm{n} \rightarrow{ }_{92}^{236} \mathrm{U} \rightarrow \text { fission fragments }+2 \text { to } 3{ }_{0}^{1} \mathrm{n}+200 \mathrm{MeV} \text {. }
$$

One of these released fission neutrons is needed for maintaining the chain reaction and out of the remaining neutrons some are captured by the fertile ${ }^{238} \mathrm{U}$ to form ${ }^{239} \mathrm{U}$ which undergoes two successive beta decays, as shown below, leading to the formation of ${ }^{239} \mathrm{Pu}$, which is an excellent fissile material:

$$
{ }_{92}^{238} \mathrm{U}+{ }_{0}^{1} \mathrm{n} \rightarrow{ }_{92}^{239} \mathrm{U} \underset{23 \cdot 5 \mathrm{~m}}{\stackrel{\beta^{-}}{\longrightarrow}}{ }_{93}^{239} \mathrm{~Np} \underset{2 \cdot 3 \mathrm{~d}}{\stackrel{\beta^{-}}{\longrightarrow}}{ }_{94}^{239} \mathrm{Pu}
$$

Thus, the nuclear reactors, apart from generating power also produce fissile ${ }^{239} \mathrm{Pu}$ as a byproduct, through neutron capture by the fertile ${ }^{238} \mathrm{U}$. Other prominent isotopes of plutonium namely ${ }^{240} \mathrm{Pu},{ }^{241} \mathrm{Pu}$ and ${ }^{242} \mathrm{Pu}$ are formed from ${ }^{239} \mathrm{Pu}$ by successive neutron captures. The isotopic content of plutonium in a thermal reactor and the formation of plutonium radionuclides and daughters depend on such factors as discharge burn-up of the fuels, neutron flux and energy spectrum, fuel enrichment, moderator to fuel volume ratio, fuel diameter, cladding materials etc., and are shown in figures 1 and 2 respectively. Typical isotopic composition of plutonium ${ }^{(3)}$ from the spent fuel elements of the $40 \mathrm{MW}$ (th) cIRUs test reactor in Trombay, the $200 \mathrm{MW}(\mathrm{e})$ boiling water reactors (BWR) at the Tarapur Atomic Power Station (TAPs) and the pressurised heavy water reactors (PHWR) at the Rajasthan Atomic Power Station (RAPS) are given in table 1.

The irradiated or the spent uranium fuel elements are a mixture of depleted uranium $\left({ }^{238} \mathrm{U}+<0.7 \%{ }^{235} \mathrm{U}\right)$, highly radioactive fission fragments and plutonium. The major

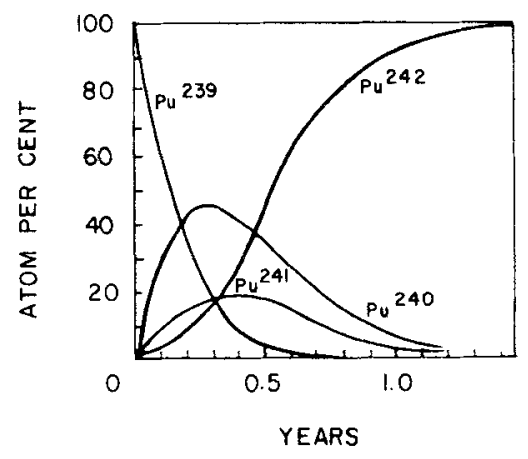

Figure 1. Plutonium isotopic composition as a function of exposure to thermal neutrons. 


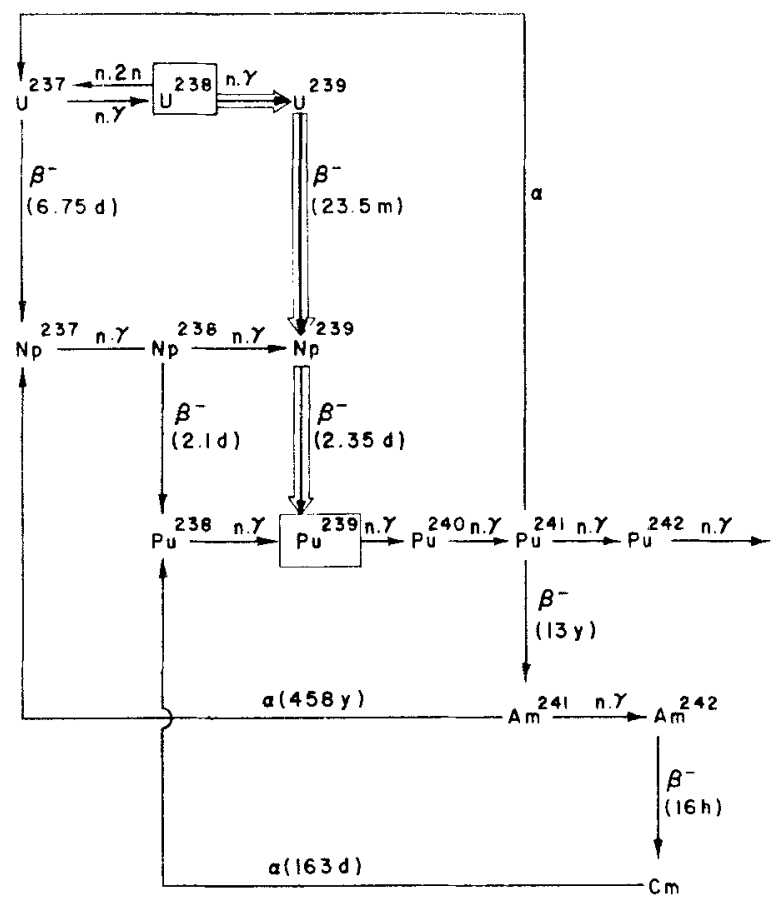

Figure 2. Plutonium radionuclides and daughters.

Table 1. Isotopic composition of plutonium from different reactors.

\begin{tabular}{|c|c|c|c|c|c|c|}
\hline Reactor & $\begin{array}{c}\text { Burn-up } \\
\text { (MWD/ton) }\end{array}$ & $\begin{array}{l}{ }^{238} \mathrm{Pu} \\
(\mathrm{w} / \mathrm{o})\end{array}$ & $\begin{array}{l}{ }^{239} \mathrm{Pu} \\
(\mathrm{w} / \mathrm{o})\end{array}$ & $\begin{array}{l}{ }^{240} \mathrm{Pu} \\
(\mathrm{w} / \mathrm{O})\end{array}$ & $\begin{array}{l}{ }^{241} \mathrm{Pu} \\
(\mathrm{w} / \mathrm{o})\end{array}$ & $\begin{array}{l}{ }^{242} \mathrm{Pu} \\
(\mathrm{w} / \mathrm{o})\end{array}$ \\
\hline BWR & 6100 & $0 \cdot 125$ & $82 \cdot 7$ & 13.94 & $2 \cdot 89$ & 0.339 \\
\hline \multirow[t]{3}{*}{ (TAPS) } & 9500 & $0 \cdot 203$ & $73 \cdot 54$ & $20 \cdot 31$ & 4.81 & $1 \cdot 080$ \\
\hline & 13750 & 0.393 & 65.77 & 25.17 & 6.45 & $2 \cdot 21$ \\
\hline & 29000 & 0.500 & $53 \cdot 40$ & $29 \cdot 60$ & $10 \cdot 48$ & 6.01 \\
\hline PHWR & 2960 & 002 & 82.52 & $15 \cdot 01$ & $2 \cdot 2$ & $0 \cdot 22$ \\
\hline \multirow[t]{2}{*}{ (RAPS) } & 5700 & 0.05 & $67 \cdot 7$ & $26 \cdot 0$ & $4 \cdot 8$ & $1 \cdot 2$ \\
\hline & 6200 & 0.06 & 66.07 & 26.87 & $5 \cdot 52$ & 1.48 \\
\hline $\begin{array}{l}\text { CIRUS } \\
\text { (Trombay) }\end{array}$ & 1000 & 0.01 & 93.32 & 6.27 & $0 \cdot 38$ & 0.02 \\
\hline
\end{tabular}

process steps (Roy 1978) in the separation of plutonium from spent fuels are shown in figure 3. After appropriate cooling for the shortlived radioactivity to die down, the spent fuel elements are transferred to a reprocessing plant where the fuel is first mechanically or chemically dejacketed from the cladding material. Next, the fuel is dissolved in nitric acid and the solution is subjected to solvent extraction for removal of fission products in the first stage and uranium in the second stage. The separated plutonium is further purified by ion-exchange process and obtained as plutonium nitrate. 


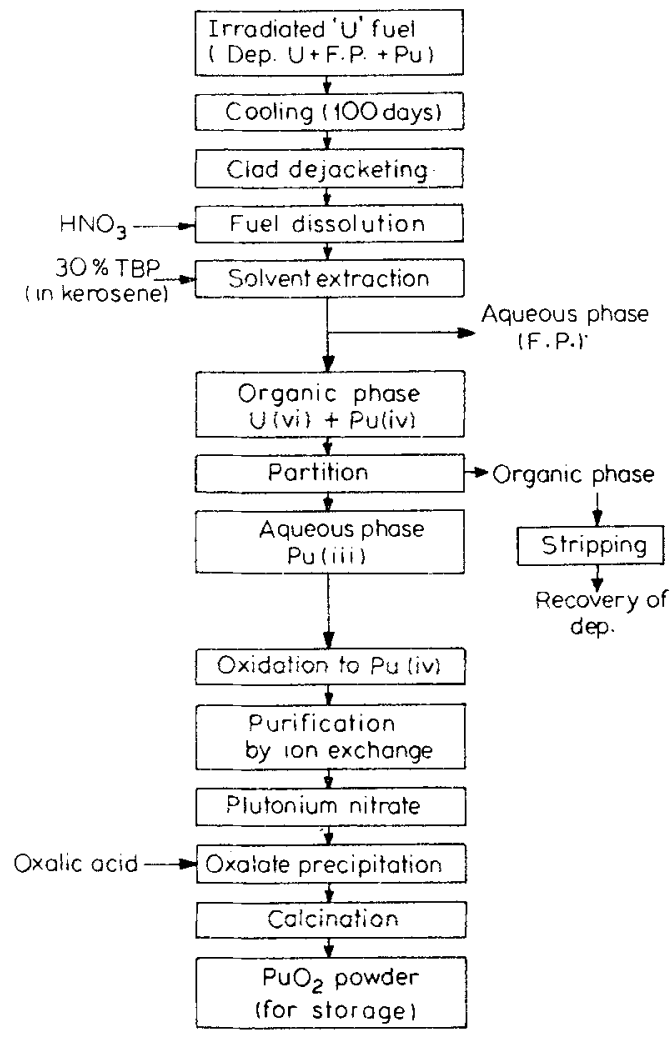

Figure 3. Flowsheet for recovery of plutonium from irradiated fuel.

The nitrate solution is converted to the oxide, mainly by the oxalate precipitation route followed by calcination in air at temperatures ranging from $400-700^{\circ} \mathrm{C}$ to get $\mathrm{PuO}_{2}$ powder suitable for subsequent use. The oxalate process has low filtrate losses, good filterability and relatively high decontamination, particularly for iron. Direct calcination of the nitrate to oxide could dispense with the intermediate precipitation process and thus achieve considerable simplification. The process has been performed satisfactorily on laboratory scale, but suffers from the drawback of complete lack of purification and decontamination which is achieved during precipitation step and thus requires a very pure feed solution.

$\mathrm{PuO}_{2}$ powder is usually the end product of a spent fuel reprocessing plant because it is most convenient to store plutonium in the form of the oxide from the point of chemical stability and ease of subsequent transportation.

\section{Safety considerations}

The high radiotoxicity, biological behaviour and fissile properties of plutonium present radiological and criticality hazards necessitating special safety considerations in handling of plutonium. In fact, this handling problem makes plutonium metallurgical operations a distinctively different and much more formidable task when compared with that of other conventional metals including uranium. Thus we had to first master 
the technique of safe handling of plutonium, either as tine powders or as bulk material, before any significant development of its metallurgy.

The decay characteristics of plutonium isotopes and their daughters are given in table 2 (Janardhanan et al 1973). ${ }^{239} \mathrm{Pu}$, the major constituent, and other isotopes of plutonium except ${ }^{241} \mathrm{Pu}$ are predominantly powerful emitters of alpha radiation. Alpha particles emitted by plutonium isotopes do not constitute an external hazard because of its short range in air and body tissue (for ${ }^{239} \mathrm{Pu}$ alphas the range in air and body tissues

Table 2. Radioactive decay characteristics of plutonium isotopes and daughters.

\begin{tabular}{|c|c|c|c|c|c|}
\hline Isotope & Radiation & Yield \% & $\begin{array}{l}\text { Energy } \\
(\mathrm{MeV})\end{array}$ & Half-life & $\begin{array}{c}\text { Specific } \\
\text { activity } \\
(\mathrm{Ci} / \mathrm{g})\end{array}$ \\
\hline Pu-238 & $\begin{array}{l}\text { Alpha } \\
\text { Gamma } \\
\text { Gamma } \\
\text { Gamma } \\
\text { L-X-ray }\end{array}$ & $\begin{array}{c}100 \\
10^{-3} \\
8 \times 10^{-3} \\
3.8 \times 10^{-2} \\
13\end{array}$ & $\begin{array}{l}5 \cdot 49 \\
0 \cdot 15 \\
0 \cdot 10 \\
0.044 \\
0.017\end{array}$ & 86.4 yr & $17 \cdot 4$ \\
\hline $\mathrm{Pu}-239$ & $\begin{array}{l}\text { Alpha } \\
\text { Gamma } \\
\text { Gamma } \\
\text { Gamma } \\
\text { Gamma } \\
\text { L-X-rays }\end{array}$ & $\begin{array}{c}100 \\
2 \times 10^{-3} \\
7 \times 10^{-3} \\
2 \times 10^{-3} \\
3 \times 10^{-3} \\
1.4 \\
2.2 \\
0.2\end{array}$ & $\begin{array}{c}5 \cdot 14 \\
0.038 \\
0 \cdot 052 \\
0.12-0 \cdot 20 \\
0 \cdot 38 \\
0.0136 \\
0.0174 \\
0.0205\end{array}$ & $2.436 \times 10^{4} \mathrm{yr}$ & 0.052 \\
\hline $\mathrm{Pu}-240$ & $\begin{array}{l}\text { Alpha } \\
\text { Alpha } \\
\text { Gamma } \\
\text { L-X-rays } \\
\text { K-X-rays }\end{array}$ & $\begin{array}{l}76 \\
24 \\
10^{-2} \\
10 \\
40\end{array}$ & $\begin{array}{c}5 \cdot 162 \\
5 \cdot 118 \\
0.044 \\
0.017 \\
0 \cdot 102-0 \cdot 125\end{array}$ & $6.58 \times 10^{3} \mathrm{yr}$ & 0.23 \\
\hline Pu-241 & $\begin{array}{l}\text { Alpha } \\
\text { Beta } \\
\text { Gamma } \\
\text { Gamma }\end{array}$ & $\begin{array}{c}3 \times 10^{-3} \\
99.997 \\
2 \times 10^{-4} \\
10^{-3}\end{array}$ & $\begin{array}{l}4 \cdot 9 \\
0.02 \\
0 \cdot 145 \\
0 \cdot 10\end{array}$ & $13.0 \mathrm{yr}$ & $111 \cdot 5$ \\
\hline $\mathrm{Pu}-242$ & $\begin{array}{l}\text { Alpha } \\
\text { Alpha } \\
\text { Gamma } \\
\text { L-X-rays }\end{array}$ & $\begin{array}{l}16 \\
24 \\
10^{-2} \\
10\end{array}$ & $\begin{array}{l}4.89 \\
4.86 \\
0.045 \\
0.017\end{array}$ & $3.79 \times 10^{5} \mathrm{yr}$ & 0.004 \\
\hline $\mathrm{U}-237$ & $\begin{array}{l}\text { Beta } \\
\text { Gamma } \\
\text { Gamma } \\
\text { Gamma }\end{array}$ & $\begin{array}{r}100 \\
61 \\
35 \\
4\end{array}$ & $\begin{array}{l}0.245 \\
0.059 \\
0.207 \\
0.334\end{array}$ & 6.75 day & $6.74 \times 10^{-4}$ \\
\hline Am-241 & $\begin{array}{l}\text { Alpha } \\
\text { Alpha } \\
\text { Gamma } \\
\text { Gamma } \\
\text { Gamma } \\
\text { Gamma } \\
\text { Gamma }\end{array}$ & $\begin{array}{l}84 \\
13.6 \\
37 \\
2.7 \\
0.05 \\
37 \\
0.02\end{array}$ & $\begin{array}{l}5.48 \\
5.43 \\
0.017 \\
0.026 \\
0.043 \\
0.059 \\
0.099\end{array}$ & $458 \mathrm{yr}$ & $3 \cdot 13$ \\
\hline
\end{tabular}


Table 3. Maximum permissible concentrations for plutonium radionuclides in body, air and water.

\begin{tabular}{|c|c|c|c|c|}
\hline \multirow{2}{*}{ Radionuclide } & \multicolumn{2}{|r|}{ MPBB } & \multicolumn{2}{|c|}{$\begin{array}{c}\text { MPC (40 hr exposure/week) } \\
(u c / c c)\end{array}$} \\
\hline & $u c$ & $u g$ & Air & Water \\
\hline $\mathrm{Pu}-238$ & 0.04 & $2.4 \times 10^{-3}$ & $2 \times 10^{-12}$ & $10^{-4}$ \\
\hline Pu-239 & 0.04 & 0.65 & $2 \times 10^{-12}$ & $10^{-4}$ \\
\hline $\mathrm{Pu}-240$ & 0.04 & 0.18 & $2 \times 10^{-12}$ & $10^{-4}$ \\
\hline $\mathrm{Pu}-241$ & 0.9 & $8.2 \times 10^{-3}$ & $9 \times 10^{-11}$ & $7 \times 10^{-3}$ \\
\hline $\mathrm{Pu}-242$ & 0.05 & $12 \cdot 8$ & $2 \times 10^{-12}$ & $10^{-4}$ \\
\hline Am-241 & 0.05 & $1.6 \times 10^{-2}$ & $6 \times 10^{-12}$ & $10^{-4}$ \\
\hline U-237 & 0.06 & 89 & $4 \times 10^{-12}$ & $9 \times 10^{-5}$ \\
\hline
\end{tabular}

are $3.68 \mathrm{~cm}$ and $40 \mu \mathrm{m}$ respectively). The primary concern in plutonium handling is to prevent particulate matter containing plutonium from entering the body of the operator through inhalation, ingestion or injection because plutonium poses the highest biological hazard when taken into the body. The long biological half-life, the high energy of the emitted alpha particles and the body's selective localisation of plutonium in the bone and lung lead to very low maximum permissible body burdens (MPBB) and maximum permissible concentrations (MPC) in air and water (table 3) (ICRP 1955). Any plutonium-bearing material is, therefore, handled in a well-ventilated laboratory within the confines of hermetically-sealed glove boxes through alpha-tight neoprene gloves. The glove box is maintained under a slightly negative pressure ( -0.2 to $-2^{\prime \prime}$ WG) under a dynamic flow of air or high purity inert gas $\left(\mathrm{N}_{2}, \mathrm{~A}\right.$ or $\left.\mathrm{He}\right)$ in order to have $3-10$ box volume changes per hour. Figure 4 gives the view of a glove box train

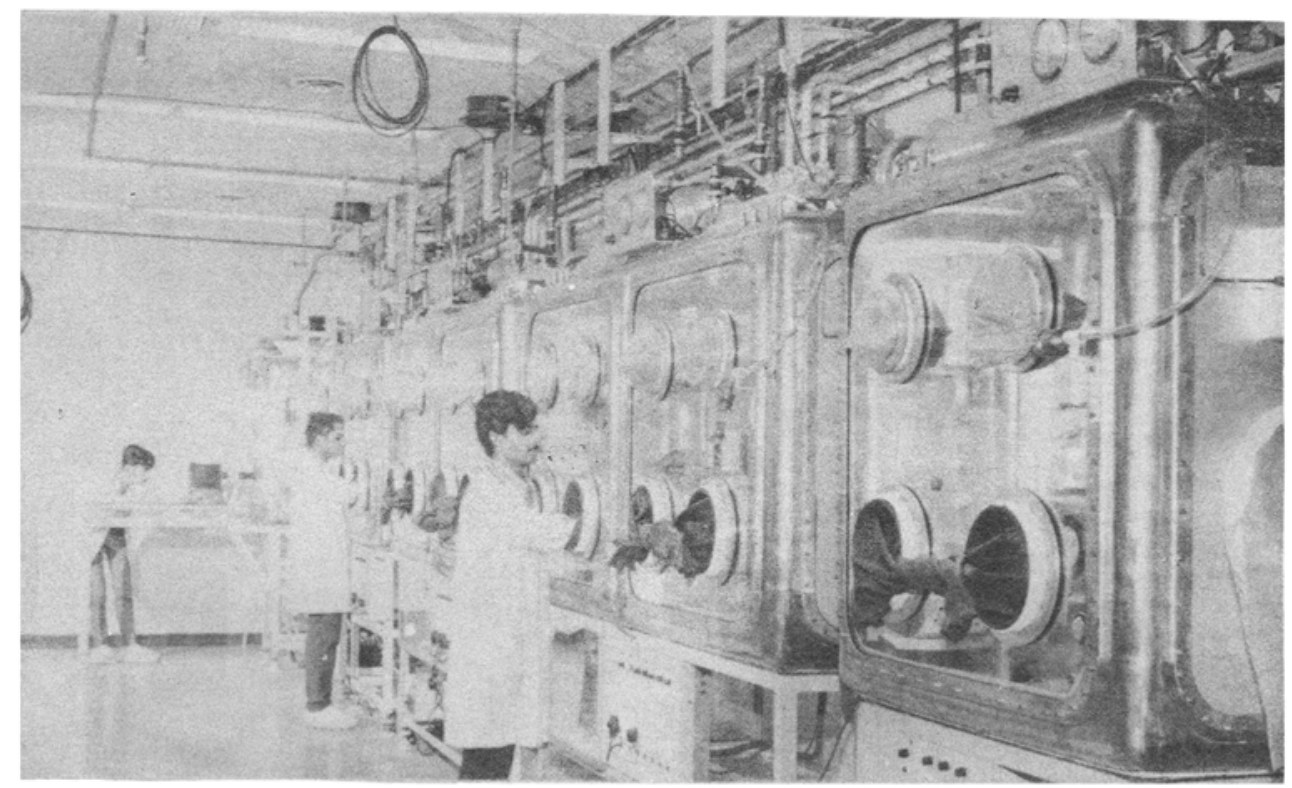

Figure 4. The 'Metallography train' of glove boxes in RMD, BARC. 
set up in the Radiometallurgy Division at Trombay for safe handling of plutonium (Ghosh et al 1973). Inert atmosphere glove boxes are used for handling plutonium metal, carbide and nitrides which are highly susceptible to oxidation and hydrolysis and are pyrophoric in powder form.

The external hazard of plutonium is mainly from gamma and neutron radiations emitted by higher isotopes of plutonium which are present in significant amounts in high burnup plutonium. The surface dose rate of plutonium since its purification increases with time because of build up of ${ }^{241} \mathrm{Am}$ and ${ }^{237} \mathrm{U}$, which are the daughter products of the beta emitting ${ }^{241} \mathrm{Pu}$. Appreciable neutron dose rates are also associated with plutonium mainly from the spontaneous fission neutrons emitted by the evennumbered plutonium isotopes, e.g. ${ }^{238} \mathrm{Pu},{ }^{240} \mathrm{Pu}$ etc., and to some extent due to $(\alpha, n)$ reactions from plutonium in contact with light elements.

In order to keep the radiation exposure of operators below the permissible limits specified by the International Commission of Radiation Protection (ICRP) the following guidelines are usually followed:

(a) restrictions are imposed on the mass of plutonium that is handled at a time, to minimise mainly the neutron dose;

(b) great emphasis is given towards automation and remotisation during handling of plutonium;

(c) close containment of plutonium bearing powder and dust such that radioactive dust does not build up on equipment and glove box surfaces;

(d) use of external or localised composite lead glass and lucite shield for gamma and neutron radiation and the use of lead-loaded neoprene gauntlets, particularly while handling high burn-up plutonium.

Unlike other metallurgical industries, in a plutonium facility a maximum of a few $\mathrm{kg}$

Table 4. Critical masses of some plutonium compounds.

\begin{tabular}{|c|c|c|c|}
\hline \multirow{2}{*}{ Compound } & \multirow{2}{*}{ Density $(g / c c)$} & \multicolumn{2}{|c|}{ Critical mass $(\mathrm{kg})$} \\
\hline & & Bare & Water reflected \\
\hline Pu-solution & - & - & 0.51 \\
\hline $\mathrm{Pu}$ & & & $\begin{array}{l}5.6 \propto \text { phase } \\
7.6 \delta \text { phase }\end{array}$ \\
\hline $\mathrm{PuO}_{2}$ & $11 \cdot 46$ & $24 \cdot 5$ & $12 \cdot 2$ \\
\hline PuN & $14 \cdot 25$ & $18 \cdot 4$ & $9 \cdot 23$ \\
\hline $\mathrm{PuC}$ & 13.6 & 17.93 & $9 \cdot 07$ \\
\hline $\mathrm{PuH}_{2}$ & $10 \cdot 4$ & $15 \cdot 64$ & $7 \cdot 49$ \\
\hline $\mathrm{PuH}_{3}$ & $9 \cdot 61$ & $12 \cdot 69$ & $6 \cdot 32$ \\
\hline $\mathrm{Pu}_{2} \mathrm{C}_{3}$ & $12 \cdot 7$ & $19 \cdot 72$ & $9 \cdot 96$ \\
\hline $\mathrm{Pu}_{2} \mathrm{O}_{3}$ & 11.47 & $24 \cdot 95$ & 12.05 \\
\hline $\mathrm{PuCl}_{3}$ & $5 \cdot 7$ & $167 \cdot 05$ & 61.59 \\
\hline $\mathrm{PuF}_{3}$ & $9 \cdot 32$ & 32.59 & $16 \cdot 0$ \\
\hline $\mathrm{PuF}_{4}$ & $7 \cdot 0$ & $56 \cdot 29$ & $25 \cdot 29$ \\
\hline $\mathrm{Pu}\left(\mathrm{C}_{2} \mathrm{O}_{4}\right)_{2}$ & $4 \cdot 5$ & 1520 & $66 \cdot 87$ \\
\hline $\mathrm{Pu}\left(\mathrm{NO}_{3}\right)_{4}$ & $6 \cdot 2$ & 103.96 & $54 \cdot 94$ \\
\hline
\end{tabular}


of fissile material is handled at a time to avoid spontaneous self-sustaining nuclear chain reaction or what is known as the criticality accident which can be catastrophic to the personnel and its surroundings. The critical mass of plutonium and its compounds depend on the geometry and the environment. Table 4 gives the critical mass of plutonium and some of its important compounds (Hansen and Clayton 1967). The upper safe limit during handling is usually kept at $50 \%$ of the critical mass.

In the plutonium metallurgy laboratory at Trombay safety has always been given priority over cost, convenience and even production capacity. As a result, there has not been a single radiation incident till todate.

\section{Nuclear parameters}

The important nuclear parameters of the three principal fissile nuclides ${ }^{235} \mathrm{U},{ }^{239} \mathrm{Pu}$ and ${ }^{233} \mathrm{U}$ are listed in table 5 (Hanna et al 1969). $\eta$, the average number of neutrons produced per neutron absorbed by the fissile nucleus is the most important parameter as it influences the conversion or breeding ratio (CR), i.e. the average number of fissile atoms produced in a reactor per fissile atom consumed by fission or capture. The conversion ratio is quantitatively expressed as:

$$
\mathrm{CR}=\eta-1-L
$$

where one neutron is needed to continue the chain reaction and $L$ represents the nonproductive absorption and leakage per neutron absorbed by fissile atom.

Since ${ }^{239} \mathrm{Pu}$ and ${ }^{233} \mathrm{U}$ have the highest $\eta$ values in the fast and thermal neutron range respectively, plutonium breeds best in a fast reactor and ${ }^{233} \mathrm{U}$ is best suited for thermal converter reactors. In fact, in a fast reactor operating on a ${ }^{238} \mathrm{U}_{-}^{239} \mathrm{Pu}$ fuel cycle, it is possible to have a breeding ratio in the range of 1.2 to 1.4 .

The other advantages of plutonium as a fissile material in fast reactors compared to ${ }^{235} \mathrm{U}$ are the higher fast fission cross-section ( $\mathrm{Pu}: 1.77$ barns; $\mathrm{U}: 1.44$ barns), $5 \%$ higher

Table 5. Nuclear properties of the principal fissile nuclides.

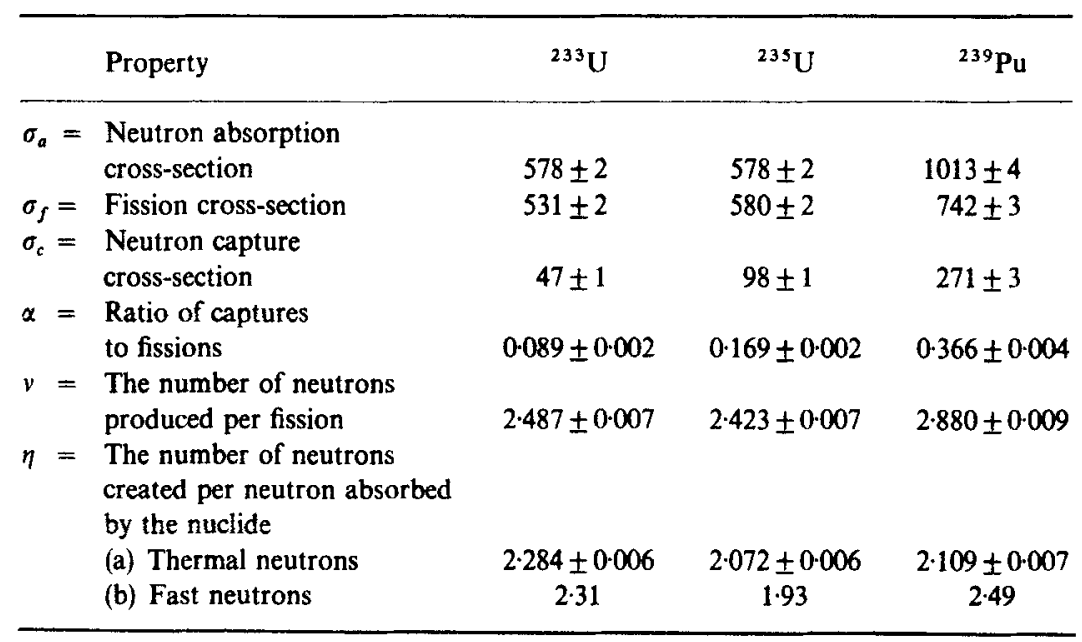

The cross-sections $\sigma_{a}, \sigma_{f}$, and $\sigma_{c}$ are in barns and $\alpha, v$ and $\eta$ are ratios. 


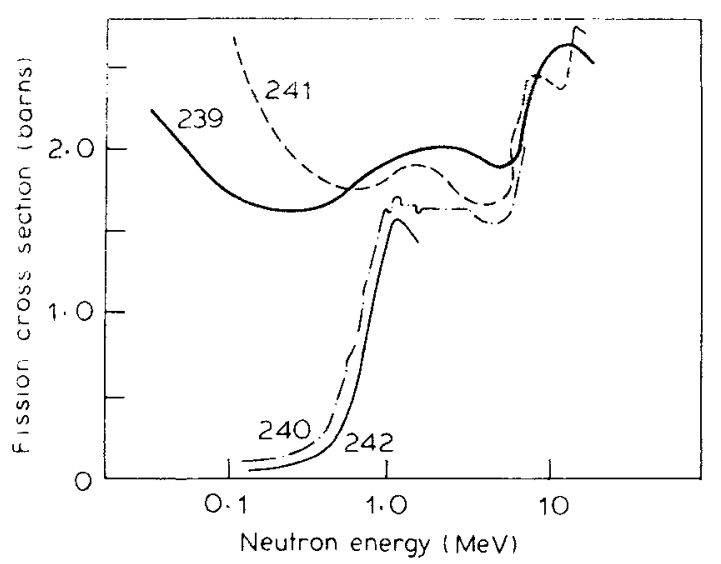

Figure 5. Fast fission cross-section (barns) of Pu isotopes

fission energy release and lower xenon poisoning. Further, ${ }^{241} \mathrm{Pu}$ is fissile in both thermal and fast neuton range and ${ }^{240} \mathrm{Pu}$ and ${ }^{242} \mathrm{Pu}$, though parasitic, neutron absorber for thermal neutrons, contribute significantly to fast fission. The fission crosssection of important plutonium isotopes in the fast neutron range is shown in figure 5 (Wick 1980).

From reactor physics consideration it may, therefore, be summarised that plutonium is the best fuel for fast reactors but is slightly inferior to ${ }^{233} \mathrm{U}$ and ${ }^{235} \mathrm{U}$ in the thermal neutron range.

\section{Plutonium metal}

\subsection{Preparation}

While starting plutonium metallurgical work at Trombay, we had already selected uranium metal as the fuel for our cIR us Research reactor. It was, therefore, logical for us to first direct all the efforts towards manufacture of high purity nuclear grade plutonium metal.

Much of the metallurgical knowledge for preparation of plutonium metal was acquired during the Manhattan Project in the 1940s. The free energy diagrams of oxide and fluoride of plutonium (Coffinberry and Miner 1961) and other metals are shown in figure 6 and table 6 gives the various thermodynamic data of the reduction reaction (Stoller and Richards 1961). Reduction of plutonium halides, in particular, fluoride and chloride remains the only method by which virtually all the metal is produced till today.

The need to obtain plutonium in massive form with a high yield dictates the choice of a reducing reaction. The reduction reaction should be accompanied by evolution of large quantity of heat which should not only melt the reaction products but also keep them molten long enough for good slag-metal separation. The reducing agent should not dissolve in plutonium or form any intermetallic compound with it. Low melting point of the slag and high boiling point of the reducing agent are additional requirements. Considering all these factors it is found that the reduction of plutonium tetrafluoride with calcium is sufficiently exothermic and the slag in this case melts at a 

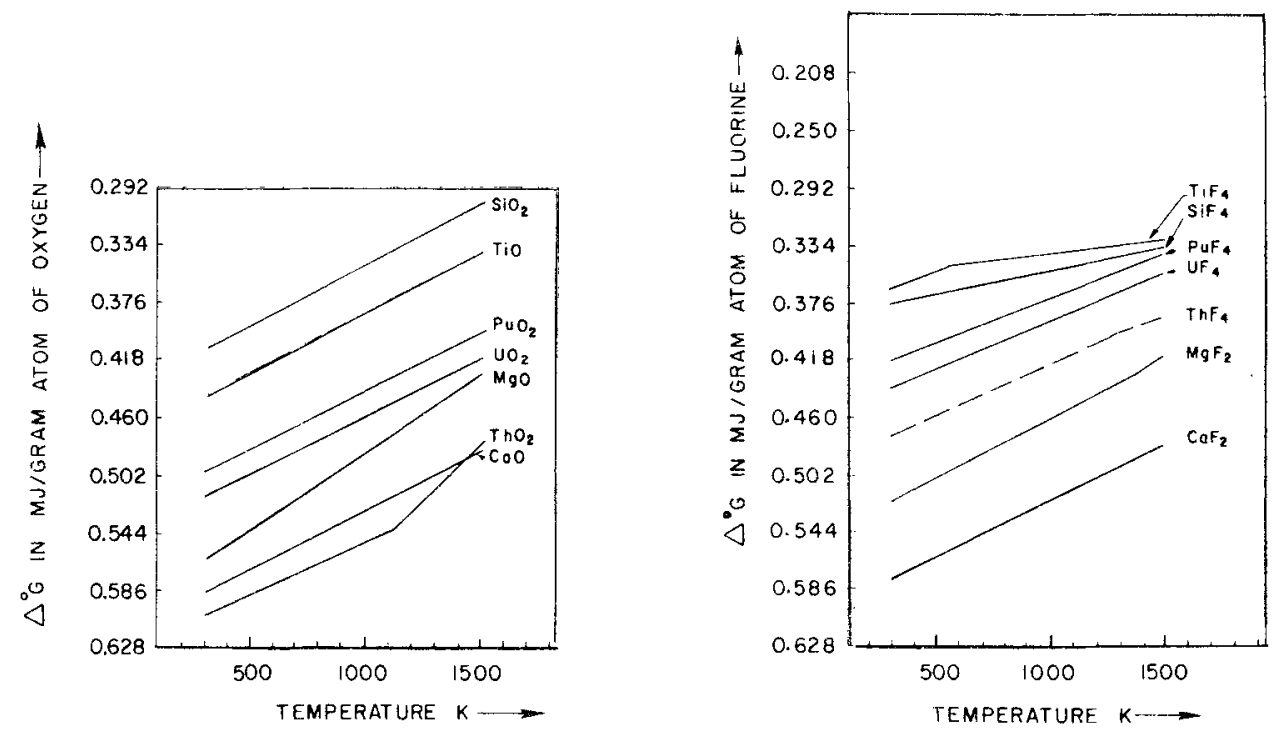

Figure 6. Standard free energy of formation $\left(\Delta G^{\circ}\right)$ for important oxides and fluorides of $U$ and $\mathrm{Pu}$.

Table 6. Thermodynamic data of the possible reduction reactions for preparation of plutonium metal

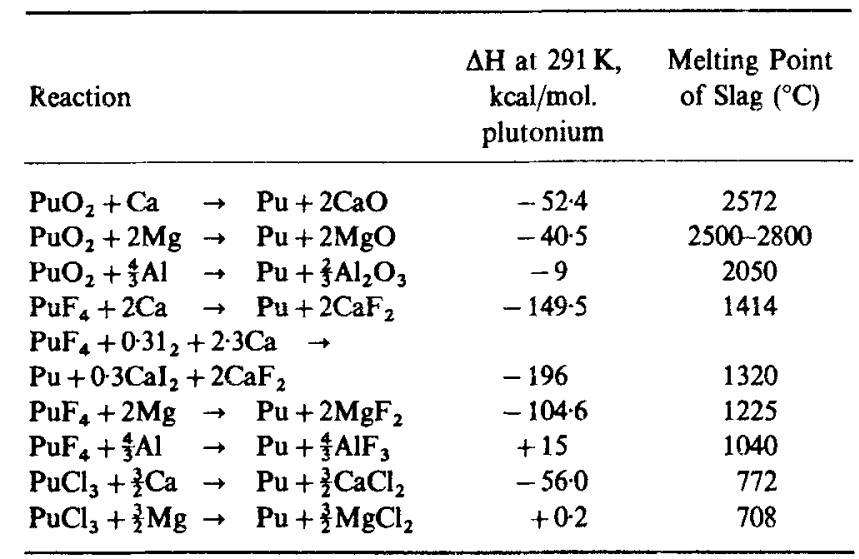

reasonably low temperature. It can be further seen that the addition of 0.3 mole of iodine makes the reaction more exothermic and also lowers the melting point of the slag by about $100^{\circ} \mathrm{C}$.

Figure 7 shows the flowsheet followed at BARC (Roy and Mahajan 1975) for the reduction of tetrafluoride with calcium. Plutonium tetrafluoride and calcium metal in amount equal to stoichiometric plus 30 to $50 \%$ excess are mixed thoroughly and charged into a steel bomb which is capable of withstanding pressures of $0.5-3 \mathrm{MPa}$ and temperature upto $1600^{\circ} \mathrm{C}$. The bomb is first purged with argon to exclude any air present. The sealed bomb is subjected to resistance or induction heating to about $600^{\circ} \mathrm{C}$ when the reduction reaction takes place and the products are melted by the heat 


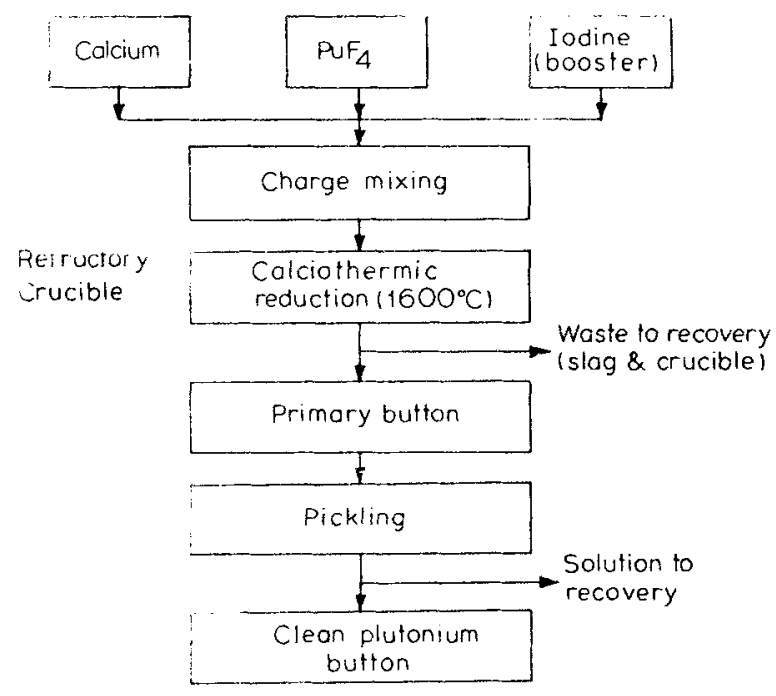

Figure 7. Hlowsheet for preparation of plutonium metal.

generated. It is very essential to control the heating rate. If the heating is too rapid, the reaction takes place only at the surface and thus the slag solidifies too rapidly. On the other hand, if preheating period is too long, the calcium particles get coated with $\mathrm{CaI}_{2}$ retarding the rate of reaction. The start of the reduction reaction is indicated by a sudden rise in the temperature monitored by a thermocouple or by a drop in the neutron emission from the reaction chamber. The yield in this process is generally $97-99 \%$ and the purity normally exceeds $99.8 \%$. Alternatively $\mathrm{PuF}_{4}$ and finely divided calcium (50\% excess) are mixed and pressed into pellets. The pellets are loaded into a calcium fluoride crucible and then in a quartz tube. On heating a bright flash shows the initiation of the reaction.

Direct reduction of dioxide would overcome the drawbacks of the fluoride and chloride processes namely high neutron emission and hygroscopicity respectively. It would also simplify the process by the elimination of the costly halogenation step. Recent studies (Wade and Wolf 1969) have shown that by proper modification of the reduction apparatus and by using a suitable flux, it is possible to obtain plutonium in massive form by calciothermic reduction of the oxide. Reduction of dioxide by carbon becomes feasible only at temperatures of the order of $3000^{\circ} \mathrm{C}$ and requires high vacuum system. It also suffers from the formation of plutonium carbide.

\subsection{Melting and casting}

The fabrication of plutonium involves many of the techniques commonly utilised for working of the common metals. However, all operations are directly affected by the extreme toxicity of plutonium in any form, the tendency of the metal to oxidise rapidly, the pyrophoricity and by the obvious necessity of avoiding conditions of criticality.

The low melting point of plutonium offers a considerable amount of freedom in the selection of melting equipment. Although resistance, arc and electron beam furnace have been used for melting plutonium, inductive heating is most advantageous. 
Extremely high reactive nature of molten plutonium poses a big problem in the choice of crucible material. Different types of crucible materials have been used. Of the metallic crucibles, tantalum has been extensively used but its use is limited to a maximum temperature of $1000^{\circ} \mathrm{C}$ after which it is rapidly dissolved by plutonium. Ceramic materials like $\mathrm{CaO}, \mathrm{Y}_{2} \mathrm{O}_{3}$ and $\mathrm{CaF}_{2}$ are good but not used because of their fragile nature. $\mathrm{Al}_{2} \mathrm{O}_{3}, \mathrm{BeO}, \mathrm{ThO}_{2}$ lead to contamination of the melt. $\mathrm{MgO}$ has been widely used but it also leads to slight contamination of the melt. Graphite has been found to be an excellent crucible material. It is inexpensive, can be easily fabricated and is not subject to thermal shock. However, a suitable coating must be applied to the graphite surface to prevent carbon pick up in the melt. Crucibles may be either tiltpouring or bottom-pouring type depending upon the type of work to be carried out.

Graphite also serves as the most commonly employed mould material. Metal moulds made of gray cast iron, mild steel, copper and for special purposes tantalum have been used.

Unalloyed plutonium has the general characteristics of a very castable material. The low melting point, high fluidity, high density and extremely small volume change on freezing are all favourable characteristics for casting. Piping and shrinkage porosity observed in most other metals are not encountered when casting plutonium. However, during cooling to room temperature a number of phase transformations take place in pure plutonium metal some of which are accompanied by large volume changes. Accordingly extreme care is exercised in the design of the mould such that the casting does not adhere firmly to the mould and cause cracking. The mould is usually heated to avoid cold shuts in the casting.

\section{Aluminium-plutonium alloys}

As early as in 1961, side by side with the production of plutonium metal, we had also taken up the preparation of $\mathrm{Al}-\mathrm{Pu}$ alloys by employing similar metallothermic reduction technique (Roy 1962). This technique is particularly advantageous for plutonium alloy preparation because it eliminates costly steps of plutonium metal production, its handling in inert atmosphere and also avoids the problem of gravity segregation which is a common occurrence when a light metal like aluminium is alloyed with plutonium.

Around $500 \mathrm{mg}$ of Al-6.27\% $\mathrm{Pu}$ were prepared by aluminothermic reduction of $\mathrm{PuO}_{2}$ in the presence of excess aluminium and cryolite in a graphite crucible around $1100^{\circ} \mathrm{C}$. The reaction involved is as follows:

$$
\begin{array}{r}
3 \mathrm{PuO}_{2}+4 \mathrm{Al}=3 \mathrm{Pu}+2 \mathrm{Al}_{2} \mathrm{O}_{3}{\Delta \mathrm{G}_{1500 \mathrm{~K}}}=-42 \mathrm{kcal} / \mathrm{mol} .
\end{array}
$$

The reduced plutonium immediately alloys with the excess aluminium and the cryolite fluxes the $\mathrm{Al}_{2} \mathrm{O}_{3}$. The reaction thus proceeds in the forward direction with proper slag metal separation and high yield. The alloy thus made was recovered by breaking the graphite crucible, remelted for proper homogenisation and cast in another graphite crucible. In the very first preparation itself we could get a yield as high as $96 \%$.

No plutonium metallography facility was available in Trombay at that time. A makeshift arrangement was made for sample preparation, e.g. cutting, mounting, grinding, polishing and etching of alloy samples inside a glove box. The microscope, however, 
was kept outside the glove box and the sample was examined through a transparent plastic bag attached to the glove box. The as-cast microstructure of the alloy ingot (figure 8) clearly shows lamellar $\mathrm{PuAl}_{4}$ particles in an $\mathrm{Al}$ matrix.

$\mathrm{Al}-\mathrm{Pu}$ alloys containing 3-20 w/o plutonium have found widespread application in many research reactors. Aluminium because of its low parasitic thermal neutron absorption cross-section $(0.22 \mathrm{~b})$ and high thermal conductivity is considered as an excellent inert carrier for the fissile plutonium. Since plutonium has negligible solid solubility (Roy 1964; Ellinger et al 1962) with aluminium (figure 9) these alloys essentially comprise of a dispersion of the intermetallic $\mathrm{PuAl}_{4}$ in an aluminium matrix.

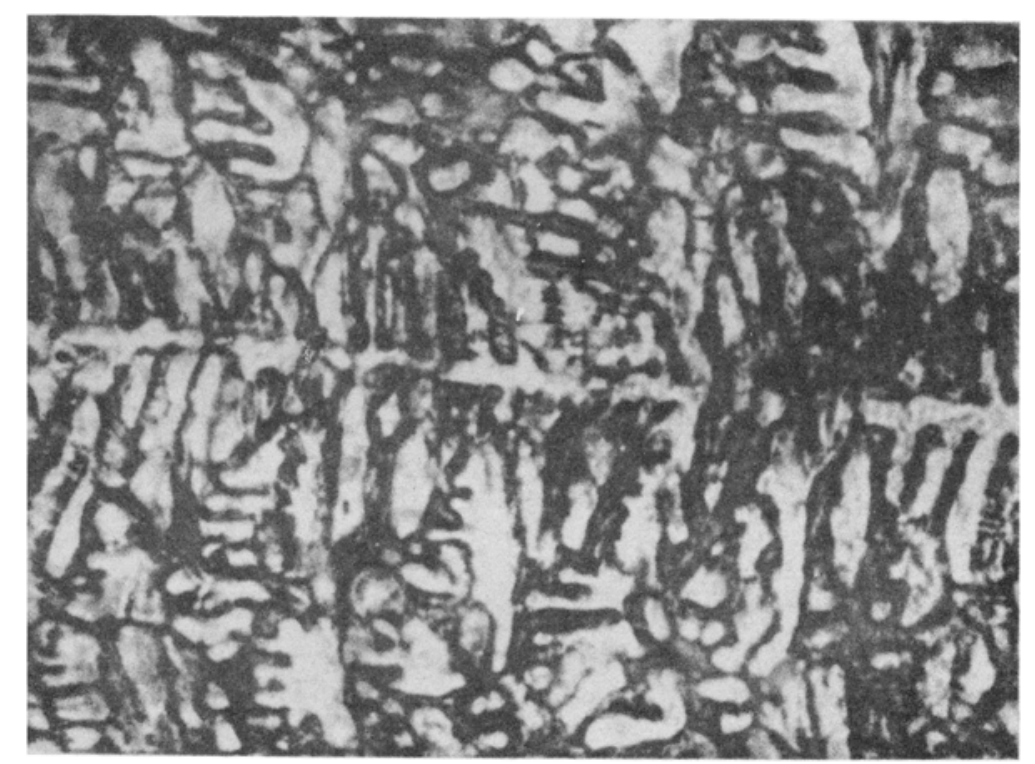

Higure 8. Microstructure of cast aluminium-plutonium alloy (prepared in $1961, \times 100$ ).

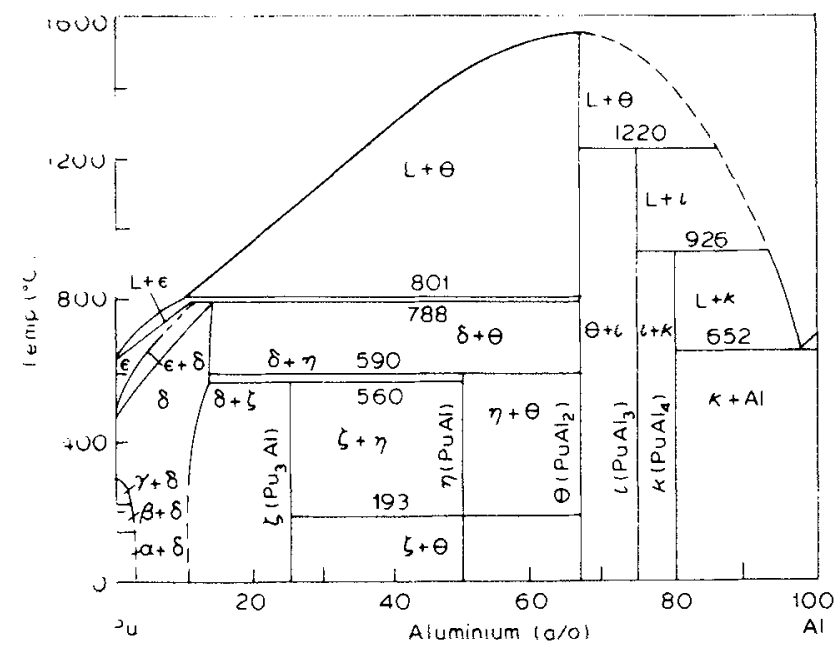

Figure 9. Plutonium aluminium phase diagram. 
Such dispersion fuel has the advantage of minimum radiation damage by restricting the fission recoil damage to the area immediately adjacent to the fissile dispersoid particles, namely $\mathrm{PuAl}_{4}$, which are relatively small in size leaving a large area of undamaged nonfissile matrix metal aluminium, which is predominant in volume and in the form of a continuous network surrounding the $\mathrm{PuAl}_{4}$ phase.

Towards the end of $1960 \mathrm{~s}, 60 \mathrm{~g}$ of $\mathrm{Al}-13 \mathrm{w} / \mathrm{O} \mathrm{Pu}$ in the form of sheets $(40 \times 40$ $\times 0.5-2 \mathrm{~mm}$ ) was prepared for nuclear physics experiments (Roy et al 1969). Experience in cold rolling of $\mathrm{Al}-\mathrm{Pu}$ alloys was obtained during this campaign.

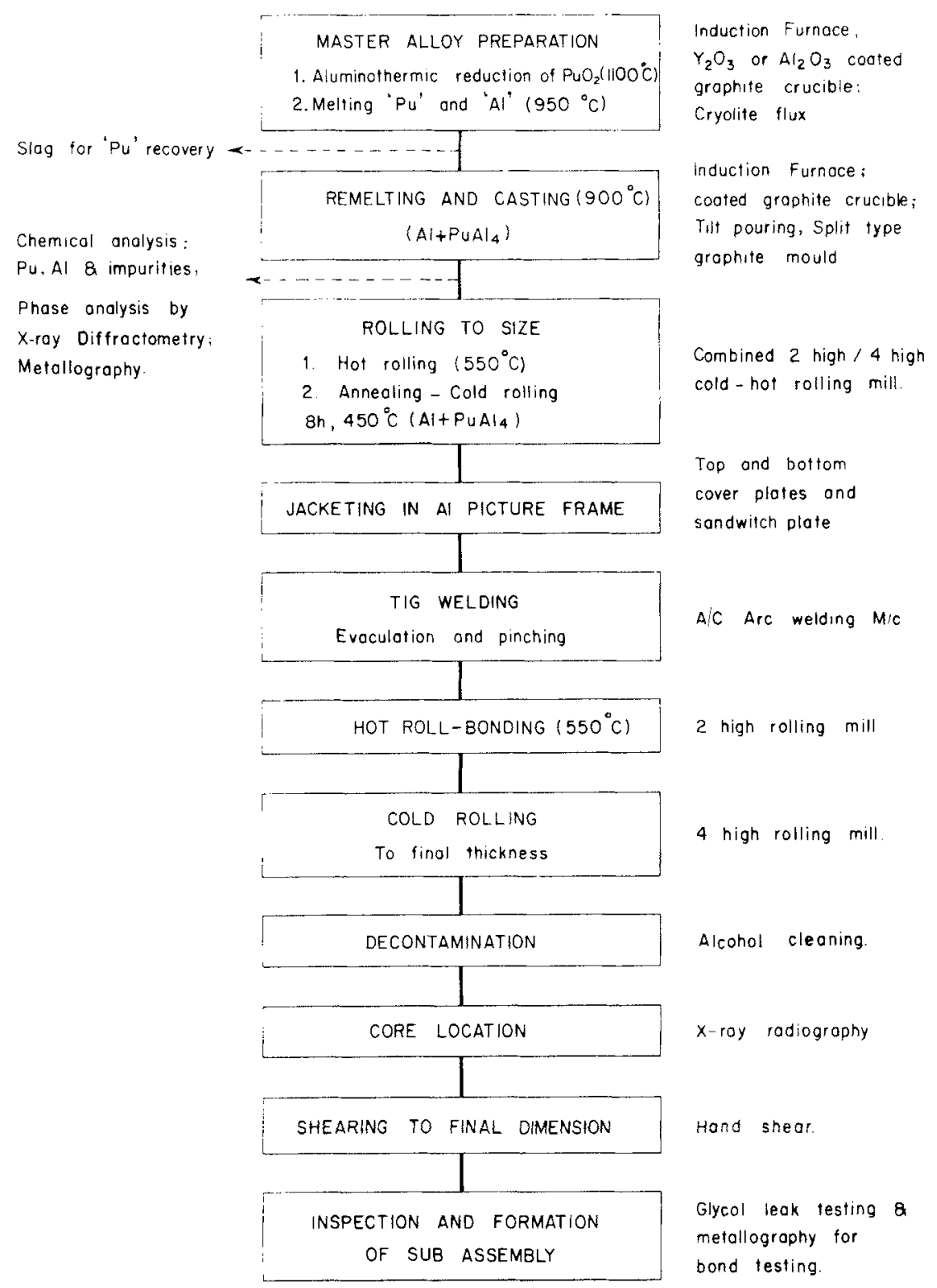

Figure 10. Flow sheet followed in BARC for fabrication of Al clad Al-Pu plate fuel element 

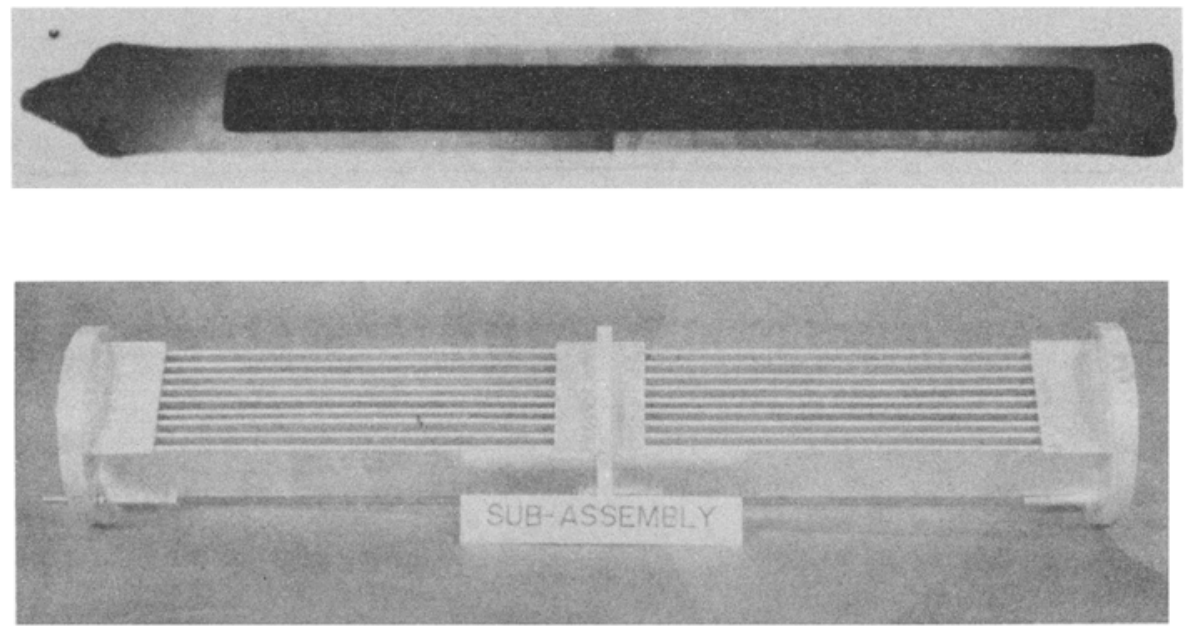

Figures 11, 12. 11. X-ray radiograph of Al clad Al-Pu alloy plate fabricated in radiometallurgy division, BARC. Dark areas show the alloy meat. 12. 9 plate fuel subassembly of Al lad Al-Pu alloy. After irradiation testing in Zerlina reactor in BARC.

With the cummissioning of the new Plutonium Metallurgy Laboratory in 1970, a new pilot scale facility was set up for fabrication of Al-Pu alloy fuel elements at BARC. The main equipment consisted of a high vacuum induction melting-casting unit, a 2 high/4 high cold/hot rolling mill and an annealing furnace.

This facility was utilised in 1973 to fabricate 2 nine plate sub-assemblies of Al-10 w/o $\mathrm{Pu}$ and Al-18 w/o Pu plate fuel elements $(445 \times 51.75 \times 1.78 \mathrm{~mm})$ by the "picture-frame technique" according to the flowsheet shown in figure 10 (Prasad et al 1976) for nuclear physics experiments in the ZERLINA reactor at BARC. The Al-Pu alloy meat was hot rollbonded to the aluminium cover plates at $450^{\circ} \mathrm{C}$. The radiograph of a roll-bonded $\mathrm{Al}$ clad Al-Pu alloy fuel plate and the photograph of a 9-plate sub-assembly fabricated at $B A R C$ are shown respectively in figures 11 and 12 .

Such Al-Pu plate fuel elements could be utilised as a substitute for the imported aluminium clad Al-13 w/o U(85 ${ }^{\circ}$ enriched $\left.{ }^{235} \mathrm{U}\right)$ plate fuels used in the Apsara Swimming Pool type test reactor at BARC. It also can be used as boosters in our pressurised heavy water reactors (PHWR) to overcome xenon poisoning following post shut-down start-ups.

\section{Plutonium-beryllium alloys}

Pu-Be alloys are used as low flux neutron sources utilising the interaction of alpha particles from plutonium with beryllium atoms to generate neutrons according to the reaction $\mathrm{Be}^{9}(\alpha, n) \mathrm{C}^{12}$. The principal advantages of $\mathrm{Pu}$-Be alloys over $\mathrm{Ra}-\mathrm{Be}$ and $\mathrm{Po}-\mathrm{Be}$ neutron sources is the stability of the neutron yield with respect to time due to the long half-life of ${ }^{239} \mathrm{Pu}(24360 \mathrm{yr})$ and the relatively small amount of low energy gamma radiation. Moreover, plutonium is relatively non-volatile as compared with radium or polonium and since it readily alloys with beryllium, it is possible to prepare the $\mathrm{Pu}$-Be neutron source as an alloy rather than pressed mechanical mixtures. The alloying further leads 
to mechanically strong, non-friable body and reproducibility in neutron yield. The neutron yield of $\mathrm{Pu}-\mathrm{Be}$ alloys, as shown in figure 13 depends on the beryllium to plutonium atom ratio $N$ according to the relation:

$$
\frac{n}{n_{\max }}=\frac{N \times S_{\mathrm{Be}}}{\left(N \times S_{\mathrm{Be}}+S_{\mathrm{Pu}}\right)}
$$

where, $n / n_{\max }$ is the fraction of maximum neutron yield, $S_{\mathrm{Pu}}$ is the stopping power of $\mathrm{Pu}$ $=4.5$ and $S_{\mathrm{Be}}$ is the stopping power of $\mathrm{Be}=0.63$. The neutron yield for a beryllium and plutonium ratio of 13, at which the alloy consists of the intermetallic $\mathrm{PuBe}_{13}$ (figure 14) is only 36.7 per $10^{6}$ alphas compared to 54.9 per $10^{6}$ alphas for an atom ratio of 200 . An atom ratio of 30 leads to good compromise between the physical size of the source and

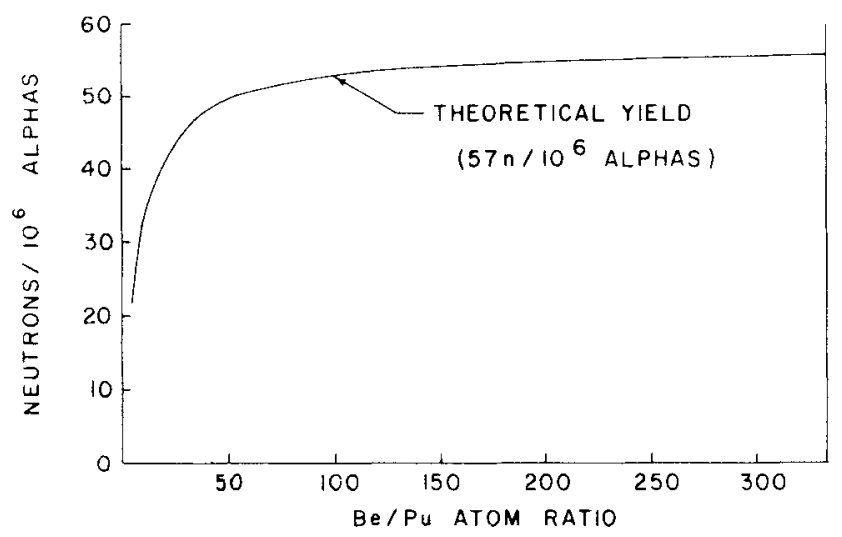

Figure 13. The variation of neutron yield with $\mathrm{Be}: \mathrm{Pu}$ atom ratio.

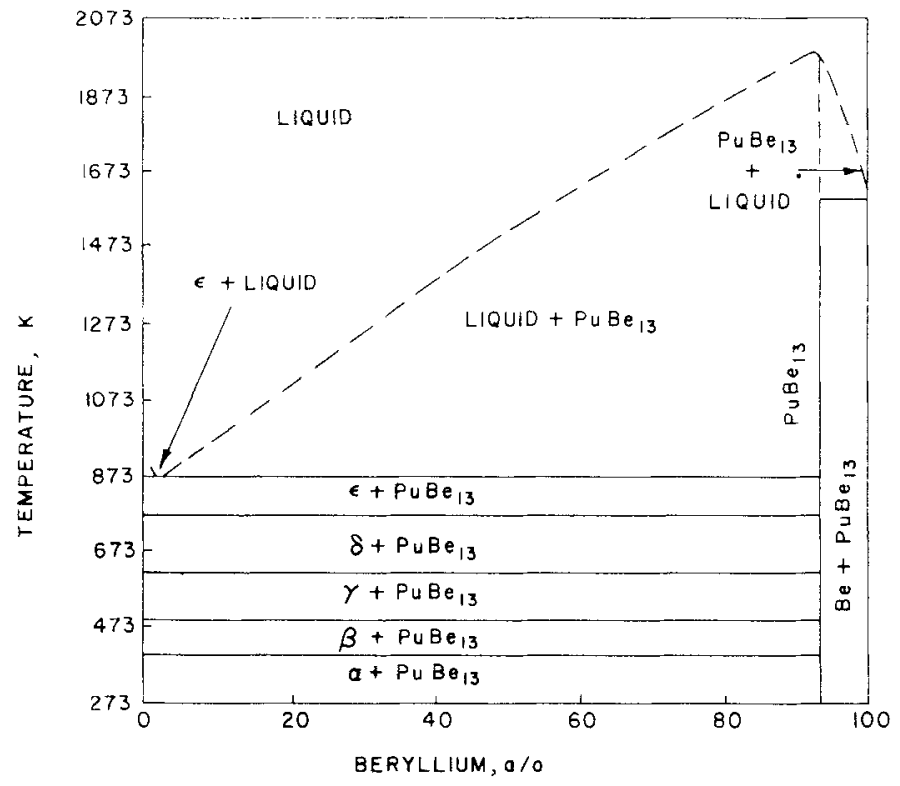

Figure 14. $\mathrm{Pu}-\mathrm{Be}$ phase diagram. 


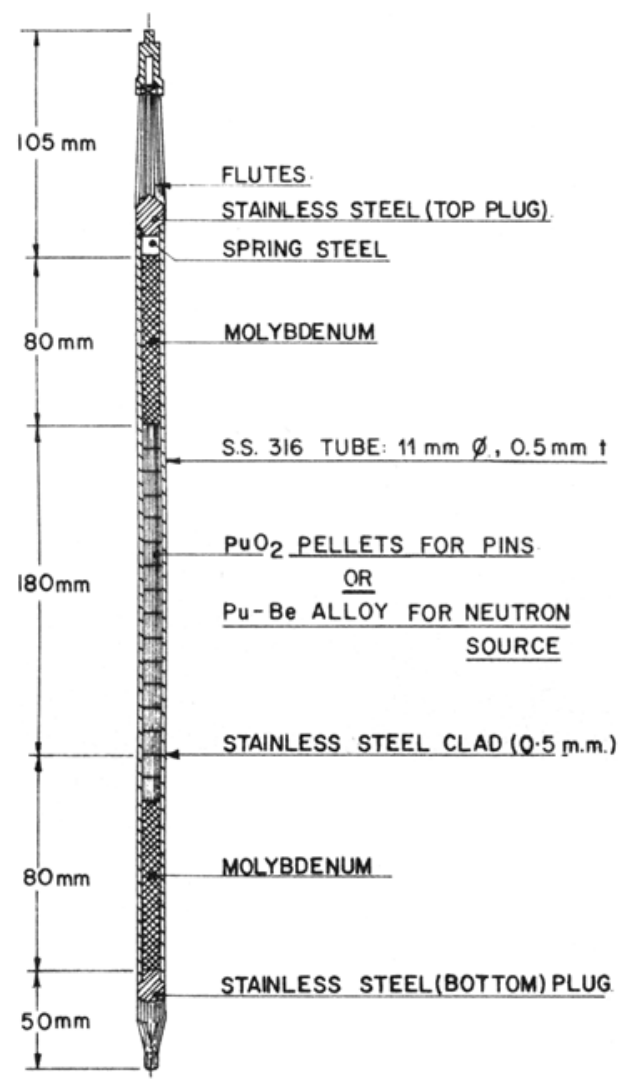

Figure 15. Fuel pin and pencil neutron source for Purnima.

its neutron yield of 46 per $10^{\circ}$ alphas. Further, alloys with $N \geqslant 30$ are easily sintered at a relative low temperature of $1250^{\circ} \mathrm{C}$ but for $N$ lower than 30 a minimum sintering temperature of $1400^{\circ} \mathrm{C}$ is required.

The first Pu-Be neutron source of nearly 1 Curie strength was prepared at BARC (Roy et al 1967) in 1967 by berylothermic reduction of pellets prepared from a powder mixture of around $18 \mathrm{~g}$ each of $\mathrm{PuO}_{2}$ and $\mathrm{Be}$ in vacuum at $1250^{\circ} \mathrm{C}(\mathrm{Be}: \mathrm{Pu}$ atom $=30)$. The reaction is as follows:

$$
\begin{aligned}
& \mathrm{PuO}_{2}+2 \mathrm{Be}=\mathrm{Pu}+2 \mathrm{BeO} \\
& \Delta G_{1000 \mathrm{~K}}=-29 \cdot 4 \mathrm{kcal} / \mathrm{mol} \text {. }
\end{aligned}
$$

The presence of $\mathrm{BeO}$ in the reaction product does not alter the neutron emission. The alloys thus prepared undergo reaction sintering and consist of a fine dispersion of $\mathrm{PuBe}_{13}$ and $\mathrm{BeO}$ in a matrix of Be. Subsequently in 1972, the same technique was followed for the preparation of several point and pencil neutron sources of strength between $50 \mathrm{mCi}$ and $5 \mathrm{Ci}$ (Mahajan et al 1972).

The $\mathrm{Pu}-\mathrm{Be}$ neutron sources are encapsulated in metallic cans. For the point source the $\mathrm{Pu}-\mathrm{Be}$ alloy tablet is first loaded in a one end closed aluminium or stainless steel container with a screwed cap. This sealed inner container is next loaded in an outer container of stainless steel and encapsulated by TIG welding. These point sources have been delivered to several agencies within and outside BARC for calibration of neutron 
counters, physics experiments and devices for measuring moisture and hydrocarbons in soil. The $900 \mathrm{mCi}$ pencil sources (figure 15) were used for start-up of the PURNIMA reactor at BARC.

\section{Delta-stabilised plutonium alloys}

Unalloyed plutonium, unlike uranium has never been tried as a nuclear fuel because of its unfavourable metallurgical properties. First, plutonium has a low melting point $\left(640^{\circ} \mathrm{C}\right)$. Secondly, there are as many as 6 allotropic transformations of plutonium between 20 and $640^{\circ} \mathrm{C}$ as shown in table 7 (Zachariasen and Ellinger 1959). No other metal shows as many phase changes within such a narrow temperature range. Particularly undesirable is the large volume change, of the order of $10 \%$, which accompanies the alpha to beta transformation at $122^{\circ} \mathrm{C}$. It was, therefore, natural to look for a high temperature phase which could be stabilised down to the room temperature by a proper combination of alloying and heat treatment.

Delta plutonium which is stable between 315 and $456^{\circ} \mathrm{C}$ has a fcc structure and exhibits the highest ductility and best formability amongst all the plutonium allotropes. The delta phase can be retained at room temperature by small additions of $\mathrm{Al}, \mathrm{Sn}, \mathrm{Zn}$, $\mathrm{Ga}, \mathrm{Zr}, \mathrm{In}, \mathrm{Hf}, \mathrm{Tl}, \mathrm{Ce}, \mathrm{Dy}, \mathrm{Er}, \mathrm{Tn}, \mathrm{La}$ or Th. The delta-stabilised plutonium has many desirable mechanical and metallurgical properties. It is ductile and soft, has a hardness value of $40-45 \mathrm{~kg} / \mathrm{mm}^{2}$ (Vicker's DPH) which is comparable to annealed copper and can be conveniently machined, worked and turned. Further, these alloys have negligible volume change during working, produce good quality casting and are more resistant to oxidation compared to unalloyed plutonium. However, the density of delta-stabilised plutonium is less than unalloyed plutonium.

Delta-stabilised plutonium alloys have been used as fuels in the first fast reactor Clementine of LASL in the late 1940s and subsequently in core IV of EBR I of ANL, ZEPHYR of Harwell and BR-1 and 2 of USSR in the early 1950s.

Delta-stabilised plutonium alloys have been prepared at BARC in the 1970s by vacuum induction melting in coated graphite crucibles and casting in graphite moulds. The principal difficulties faced in melting, and casting these alloys are gravity segregation due to large density difference between plutonium and the alloying elements and adherence of the cast alloy with the mould because of negligible solidification shrinkages of delta plutonium.

Table 7. Allotropes of plutonium and their properties.

\begin{tabular}{llcccr}
\hline Phase & Structure & $\begin{array}{c}\text { Stability } \\
\text { range } \\
\left({ }^{\circ} \mathrm{C}\right)\end{array}$ & $\begin{array}{c}\text { Density } \\
(\mathrm{g} / \mathrm{CC})\end{array}$ & $\begin{array}{c}\text { Coeff. of } \\
\text { expansion (micro } \\
\left.\text { in./in. }{ }^{\circ} \mathrm{C}\right)\end{array}$ & $\Delta V \%$ \\
\hline$\alpha$ & $\begin{array}{l}\text { Simple monoclinic } \\
\beta\end{array}$ & Up to 117 & 19.84 & 48.4 & $10 \cdot 10$ \\
& $\begin{array}{l}\text { Body centred mono- } \\
\text { clinic }\end{array}$ & $117-213$ & 17.8 & 38.0 & 2.58 \\
$\delta$ & Face centred & & & & \\
$\delta$ & orthorhombic & $213-315$ & 17.14 & 34.7 & 6.75 \\
$\delta^{\prime}$ & foc & $315-456$ & 15.92 & -8.8 & -0.25 \\
$\varepsilon$ & bct & $456-475$ & 16.01 & -116.0 & -3.0 \\
\hline
\end{tabular}




\section{Plutonium dioxide}

In the field of ceramic fuel too the trend developed in the uranium system had set the pattern in the plutonium field. In the 1960s uranium dioxide was universally used in most of the commercial thermal power reactors, including ours, and the technology for the production of zircaloy clad $\mathrm{UO}_{2}$ fuels by the "pellet-in-tube" process was available in Trombay (Fareeduddin et al 1975). This know-how was conveniently extended for the initial development of stainless steel clad $\mathrm{PuO}_{2}$ fuels in the new plutonium metallurgy laboratory at Trombay in 1970 (Roy 1975).

Subsequently, the first major plutonium fuel fabrication job was executed in 1972 when the complete core for the zero energy fast reactor PUR NIMA in BARC consisting of 186 fuel pins containing around $25 \mathrm{~kg}$, of sintered $\mathrm{PuO}_{2}$ fuel pellets was fabricated. The fuel pin ( $495 \mathrm{~mm}$ long $\times 11 \mathrm{~mm}$ OD) (figure 15) with a cladding thickness of $0.5 \mathrm{~mm}$ and consists of a stack of sintered $\mathrm{PuO}_{2}$ fuel pellets of average density of $90 \%$ theoretical, held tight by a spring between a pair of axial molybdenum reflectors in a 316 stainless steel cladding tube which is sealed leak tight by TIG welded end plugs.

$\mathrm{PuO}_{2}$ pellets were prepared from oxalate derived sinterable $\mathrm{PuO}_{2}$ powder by the powder metallurgy route of cold compaction at around $25 \mathrm{TSI}$ followed by sintering at $1600^{\circ} \mathrm{C}$ in $\mathrm{A}+8 \% \mathrm{H}_{2}$ atmosphere. The finished fuel pins were subjected to rigorous inspections for dimensional checks, $\mathrm{x}$-ray radiographic examinations, mass spectrometric helium leak detection and surface contamination.

\section{Mixed oxide fuels}

Pure $\mathrm{PuO}_{2}$ as such is not suitable for use as fuel in power generating reactors as it fails to satisfy the reactor engineering and safety requirements of bigger reactors. Further, for breeding additional fissile material simultaneously with power generation it is essential to dilute $\mathrm{PuO}_{2}$ by mixing with fertile materials like $\mathrm{UO}_{2}$ or $\mathrm{ThO}_{2}$.

The following mixed oxide fuel compositions have been studied and developed in the last ten years as a part of our fuel development programme for water-cooled thermal and liquid metal cooled fast breeder reactors (LMFBR):

(a) $76 \% \mathrm{PuO}_{2}-24 \%$ natural $\mathrm{UO}_{2}$ or $70 \% \mathrm{UO}_{2}-30 \% \mathrm{PuO}_{2}$ (assuming availability of $85 \%$ enriched ${ }^{235} \mathrm{U}$ for actual use) fuels for our fast breeder test reactor (FBTR).

(b) $\mathrm{UO}_{2}-\mathrm{PuO}_{2}$ (up to a maximum of $5 \mathrm{w} / \mathrm{o} \mathrm{PuO}_{2}$ ), popularly known as the MOX fuel, as substitute for the $2-4 \%$ enriched $\mathrm{UO}_{2}$ fuels for the BWRs at TAPS.

Since $\mathrm{UO}_{2}$ and $\mathrm{PuO}_{2}$ are isostructural (fcc, $\mathrm{CaF}_{2}$ type), mutually solid soluble and have similar physical and chemical properties (table 8), the fabrication flowsheets (figure 16) of the mixed oxides are essentially the same and involves three major steps, namely, (i) simultaneous mixing grinding of the two oxide powders in the desired proportion, (ii) cold compaction of the powder mixture into pellets with or without binder addition, and (iii) sintering the pellets in a controlled atmosphere. The process control steps in pellet fabrication should ensure homogeneous solid solution formation, uniform distribution of plutonium, an oxygen to metal ratio slightly in the hypostoichiometric range and a controlled density.

In addition to the above route, in Trombay we are also working on the "vibrosol" process as an alternative method of preparation of mixed oxide fuel pins (Sood and 
Table 8. Selected properties of U, Pu and Th compounds.

\begin{tabular}{|c|c|c|c|c|c|c|c|}
\hline \multirow{2}{*}{ Property } & \multicolumn{3}{|c|}{ Oxide } & \multicolumn{2}{|c|}{ Carbide } & \multicolumn{2}{|c|}{ Nitride } \\
\hline & $\mathrm{UO}_{2}$ & $\mathrm{PuO}_{2}$ & $\mathrm{ThO}_{2}$ & UC & PuC & UN & PuN \\
\hline Theoretical density $\left(\mathrm{g} / \mathrm{cm}^{3}\right)$ & $10 \cdot 96$ & 11.46 & $10 \cdot 00$ & 13.63 & $13 \cdot 60$ & $14 \cdot 32$ & $14 \cdot 25$ \\
\hline Metal density $\left(\mathrm{g} / \mathrm{cm}^{3}\right)$ & $9 \cdot 66$ & $10 \cdot 10$ & 8.79 & $12 \cdot 97$ & $12 \cdot 95$ & $13 \cdot 52$ & 13.46 \\
\hline Metal fraction (w/o) & $88 \cdot 15$ & $88 \cdot 19$ & 87.89 & $95 \cdot 20$ & $95 \cdot 20$ & $94 \cdot 44$ & $94 \cdot 46$ \\
\hline Melting point (K) & 3000 & 2675 & 3640 & 2780 & 1875 & 3125 & 2840 \\
\hline $\begin{array}{l}\text { Thermal conductivity } \\
\text { (W/cm K) } \\
\text { for } 100 \% \text { TD material }\end{array}$ & & & & & & & \\
\hline $1000 \mathrm{~K}$ & 0.052 & 0.034 & 0.062 & 0.199 & $0 \cdot 108$ & $0 \cdot 185$ & $0 \cdot 146$ \\
\hline $1500 \mathrm{~K}$ & 0.035 & 0.023 & 0.024 & 0.213 & 0.142 & 0.248 & $0 \cdot 167$ \\
\hline $2000 \mathrm{~K}$ & 0.022 & 0.018 & - & $0 \cdot 225$ & $0 \cdot 159$ & $0 \cdot 270$ & 0.184 \\
\hline
\end{tabular}

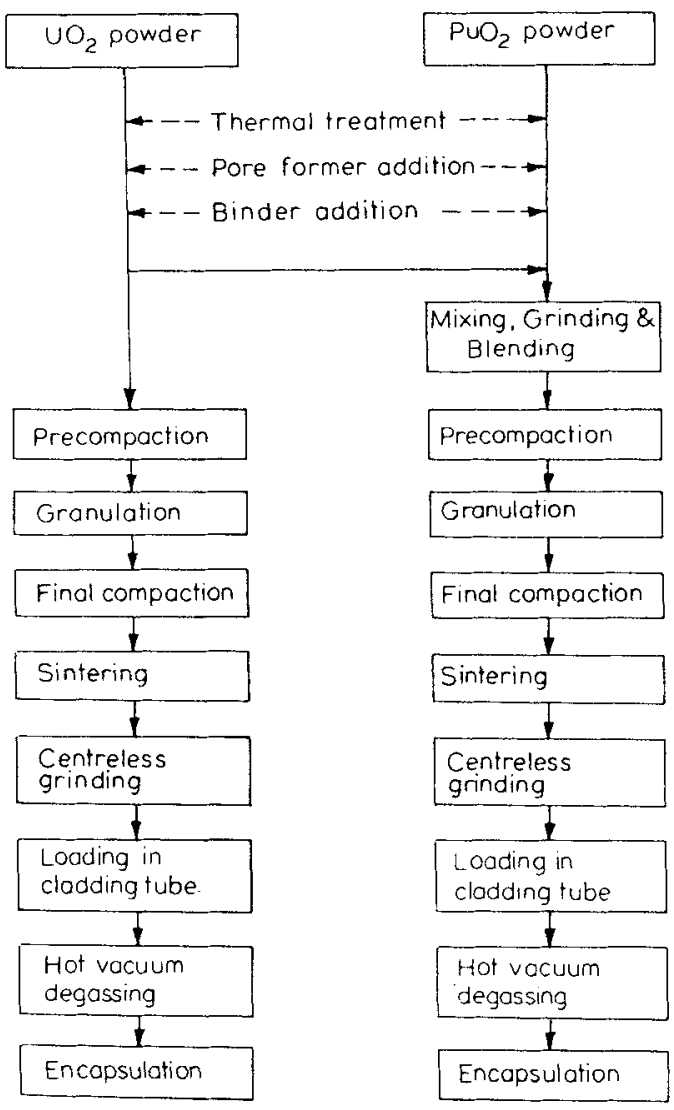

Figure 16. Process flow sheet for $\mathrm{UO}_{2}$ and $\mathrm{UO}_{2}-\mathrm{PuO}_{2}$ pellet fuel pin.

Vaidya 1979). This method consists of preparing mixed oxide gels by a "wet chemical route" starting from uranyl and plutonium nitrate solutions followed by calcination of the gels to get mixed oxide microspheres of high density ( $\sim 98 \%$ TD). By blending microspheres of different size fractions in the range of $10-100 \mu \mathrm{m}$ and packing them in 
the fuel pin by "vibratory compaction", smear density of the fuel pin can be controlled between 60 and $90 \%$ TD. An "internal gelation" (Kanij et al 1974) process has been followed for preparing mixed oxide microspheres according to the flowsheet shown in figure 17. The nitrate solutions of the actinides are mixed and cooled. To this, concentrated hexamethylene tetra amine (HMTA) and urea solutions are added which act as internal gelation agents. Droplets of this solution are gelled by contact with hot $\left(\sim 90^{\circ} \mathrm{C}\right)$ silicone or paraffin oil.

The vibro-sol method offers the following advantages over the cold pressing sintering process:

(a) There are less number of fabrication steps and maximum flexibility of operation.

(b) A high degree of microhomogeneity is obtained in the microsphere since the

blending is effected in the liquid stage and steps like prolonged ball milling of oxide powders for achieving good homogenisation are avoided.

(c) The build-up of radioactive dust on equipment and glove box surfaces which is rather common in the powder metallurgy route is also avoided since no fine powder handling is involved.

(d) The method is more suitable for remote operation and automation.

The main drawback of the vibro-sol route is that in the event of an accidental breach of the cladding tube, there could be more expulsion of fuel particles to the coolant circuit as compared to pellet fuel, thereby causing a gross contamination of the primary coolant.

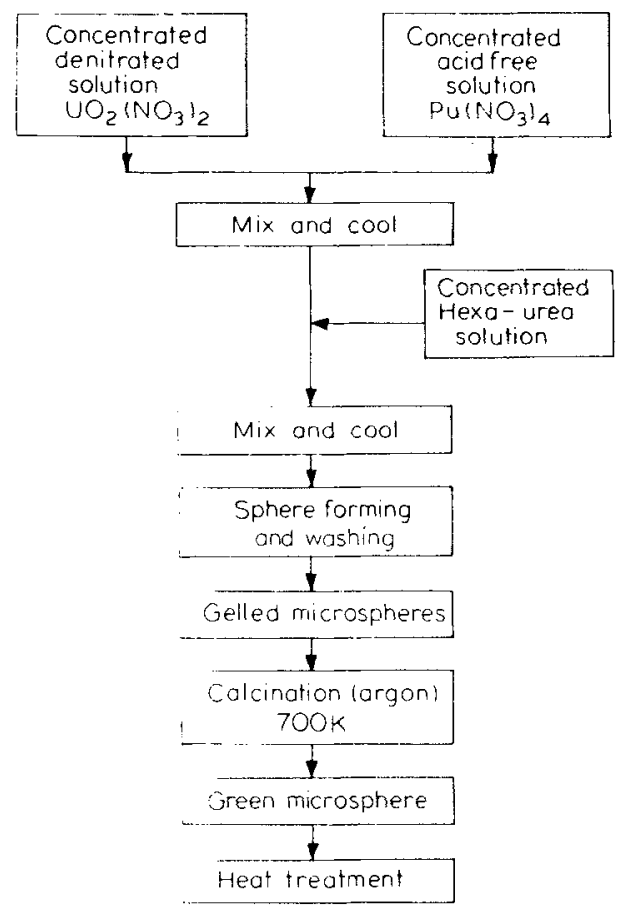

Figure $1 \%$ the kema internal gelation process. 


\section{$10.1 \mathrm{UO}_{2}-\mathrm{PuO}_{2}$ for LMFBRS}

As a first step of our venture in the LMFBR technology a decision was taken in the 1970s to set up a small $42.5 \mathrm{MW}$ (th) fast breeder test reactor (FBTR), similar to the RapsodieFortissimo reactor of France, at the Reactor Research Centre, Kalpakkam. It was also decided to fabricate the fuel for this reactor in Trombay from our available natural uranium resources and plutonium. Normally, in such small test reactors the fissile requirement of the core, as shown in figure 18, is met by enriched uranium along with plutonium in order to have a high neutron flux level and to compensate for the neutron leakage loss in the small core. However, we preferred to replace the ${ }^{235} \mathrm{U}$ completely by plutonium and consequently looked into the possibility of using $76 \% \mathrm{PuO}_{2}-24 \% \mathrm{UO}_{2}$ in place of already proven $70 \% \mathrm{UO}_{2}$ (enriched to $85 \%{ }^{235} \mathrm{U}$ ) $-30 \% \mathrm{PuO}_{2}$ fuel of Rapsodie.

Unfortunately, preliminary metallurgical investigations revealed that $\left(\mathrm{U}_{0.24} \mathrm{Pu}_{0 \cdot 76}\right) \mathrm{O}_{2}$ was not compatible with the sodium coolant and led to the formation of $\mathrm{Na}_{3}(\mathrm{U}, \mathrm{Pu}) \mathrm{O}_{4}$ with accompanying high swelling as shown in figure 19(a) (Internal Report 1970; Housseau 1974). The sodium-fuel interaction and in turn the swelling could be significantly reduced if the $\mathrm{O} / \mathrm{M}$ ratio of the fuel was kept around 1.8 (figures $19 \mathrm{~b}, \mathrm{c})$ but then the already low thermal conductivity of the plutonium rich oxide fuel further reduces by nearly $30 \%$ (figure 20) (Internal report 1974). Moreover, the mixed oxide fuel of this composition with an optimum $\mathrm{O} / \mathrm{M}$ ratio of 1.98 and pellet density of $92 \%$ TD always had a two-phase microstructure at room temperature as shown in the $\mathrm{x}$-ray diffraction pattern (figure 21) and photomicrograph (figure 22) (Ramachandran et al 1981).

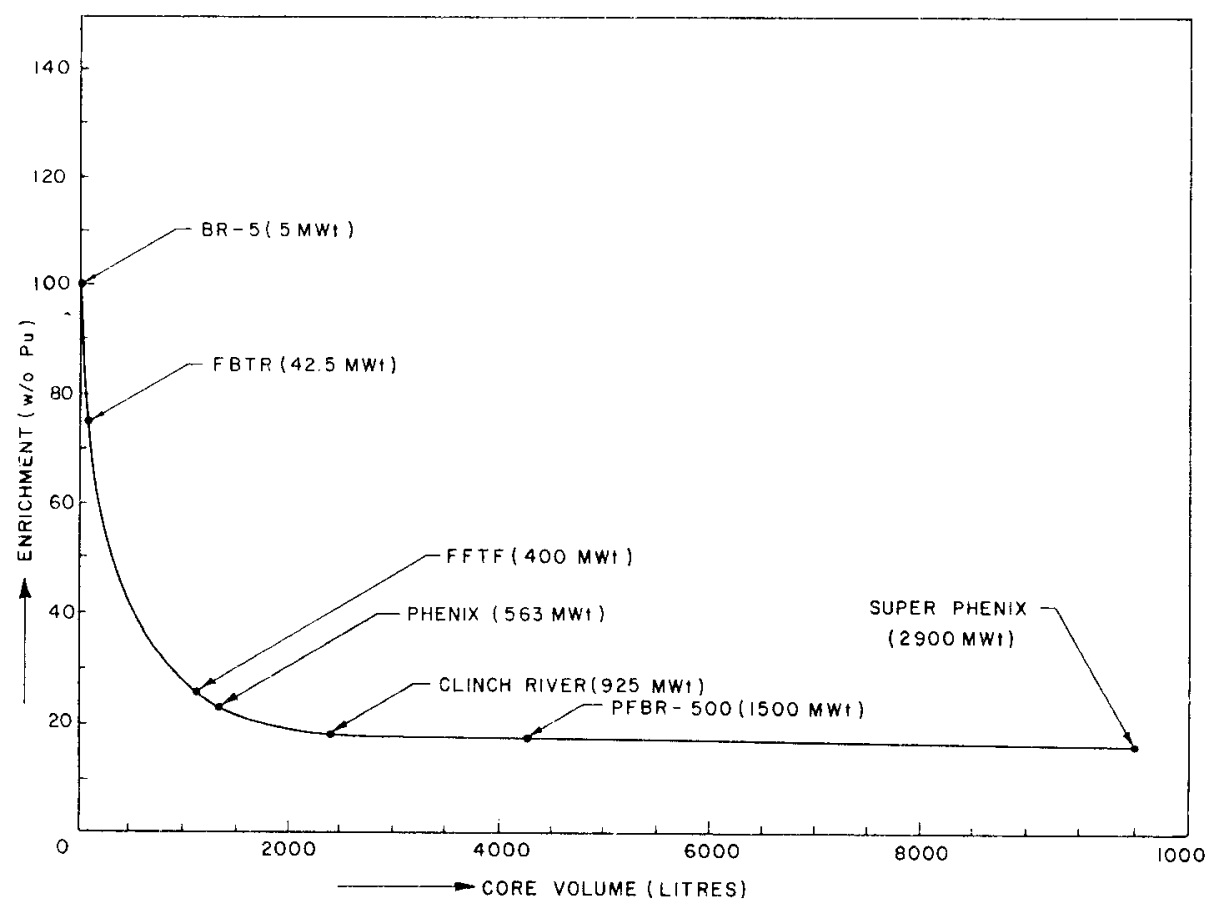

Figure 18. Enrichment-core volume. 


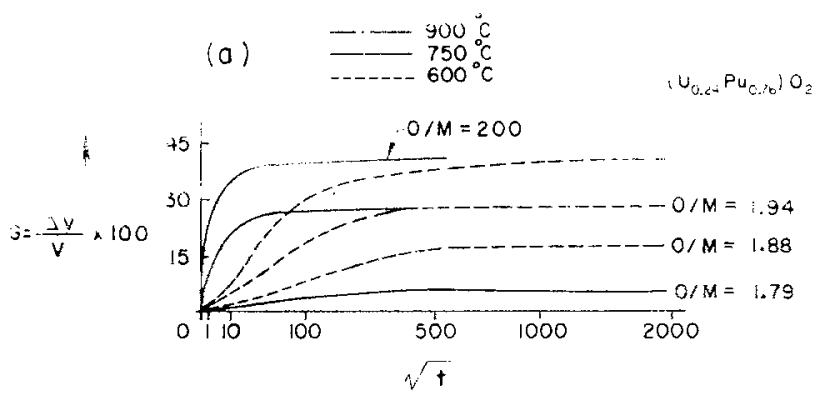

$\left(U_{0.7} \mathrm{Pu}_{0.3}\right)^{\mathrm{O}_{2}}$
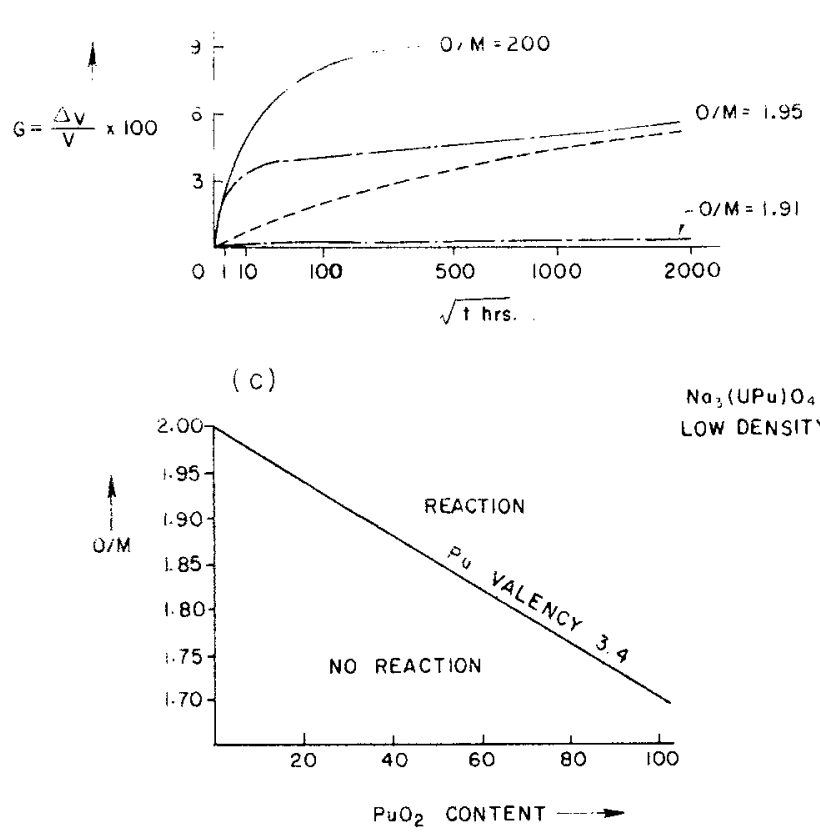

Figure 19. Swelling of uranium and plutonium rich mixed oxide after interaction with sodium.

In view of the above deficiencies, investigation of plutonium rich $(\mathrm{U}, \mathrm{Pu}) \mathrm{O}_{2}$ was not pursued further. The next logical step was to revert back to the development of fabrication flowsheet of $70 \% \mathrm{UO}_{2}-30 \% \mathrm{PuO}_{2}$. Single-phase mixed oxide pellets of this composition with density $92 \% \mathrm{TD}$ and $\mathrm{O} / \mathrm{M}$ ratio 1.98 could be reproducibly fabricated in our laboratory (Majumdar et al 1984). A typical microstructure of single phase mixed oxide pellet is shown in figure 23.

\subsection{MOX fuel for TAPS}

Zircaloy -2 clad $2-4 \%$ enriched $\mathrm{UO}_{2}$ is the fuel for the two BWR at TAPS. The enriched uranium for these reactors was imported ever since the reactors were commissioned in 1967. However, with changing political conditions great difficulties were experienced in 


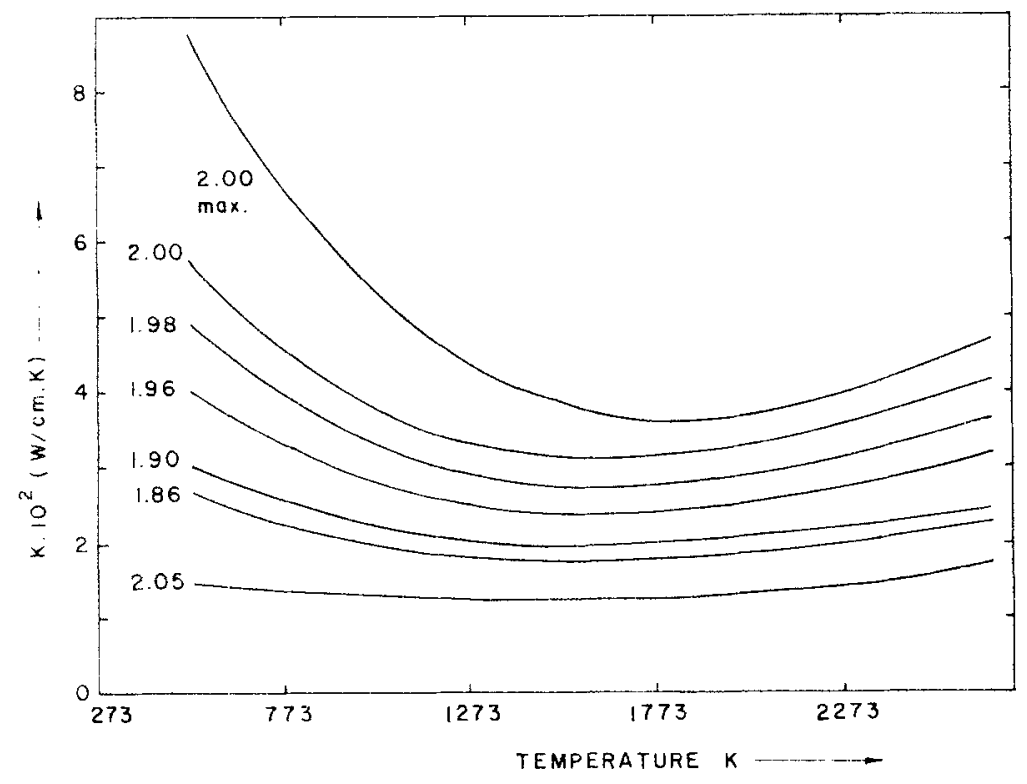

Figure 20. Thermal conductivity vs. temperature of $76 \% \mathrm{PuO}_{2}-24 \% \mathrm{UO}_{2}$ pellets of different stoichiometry.

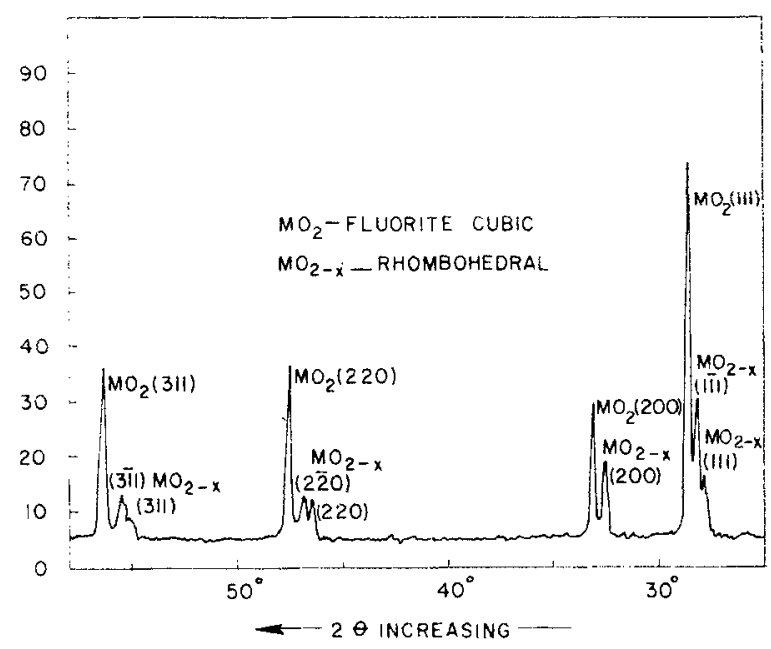

Figure 21. XRD pattern of $\left(\mathrm{U}_{0.24} \mathrm{Pu}_{0.76}\right) \mathrm{O}_{2-x}$ sintered pellet.

importing enriched uranium and a decision was taken in 1978 to explore the possibility of fabricating indigenously Mox fuel containing 2-5 w/o $\mathrm{PuO}_{2}$ as a substitute for the enriched $\mathrm{UO}_{2}$ fuel. Accordingly, a crash programme was launched to augment the existing plutonium fuel fabrication laboratory with a capacity of $1 \mathrm{~kg}$ fuel per day to $50 \mathrm{~kg}$ per day to meet the interim requirement of TAPS. 

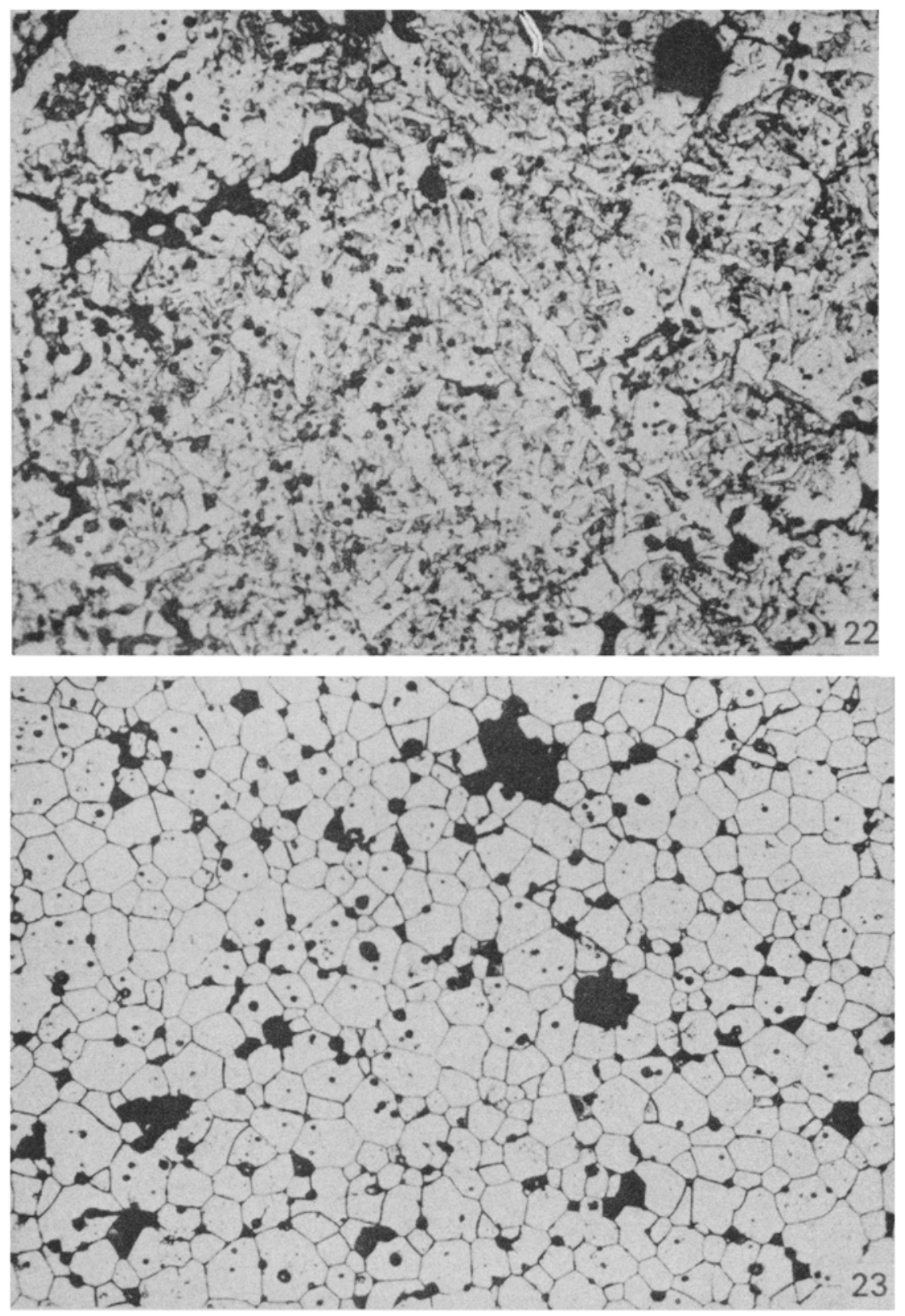

Figures 22, 23. 22. Microstructure of $\left(\mathrm{U}_{0.24} \mathrm{Pu}_{0.76}\right) \mathrm{O}_{2}$ showing two phases $(x 400)$. 23. Microstructure of single phase $\left(\mathrm{U}_{0.70} \mathrm{Pu}_{0.30}\right) \mathrm{O}_{2}(\times 320)$.

Though the first mox fuel experience (Sah et al 1977) was acquired in Trombay in 1972 when a test pin of $\mathrm{UO}_{2}-1.5 \mathrm{w} / \mathrm{o} \mathrm{PuO}_{2}$ of specifications similar to our PHWR fuel element was fabricated for irradiation testing in the pressurised water loop (PWL) of our CIRUS reactor, the MOX substitute fuel for TAPS was a real challenge to the metallurgists as 
this was a time bound project involving plant scale handling and fabrication of plutonium fuels in a laboratory originally designed for $\mathrm{R}$ and $\mathrm{D}$ work only.

After extensive investigation, fabrication flowsheet with optimum process parameters was developed to get mox fuel pellets according to specification (Roy et al 1984). There is a stringent requirement of uniformity of plutonium distribution in the fuel pellets from the view point of in-reactor performance. This has been confirmed from the alpha-autoradiography of the mox pellets shown in figure 24 .

The pilot scale Mox fuel fabrication facility of capacity $50 \mathrm{~kg}$ sintered Mox pellets per day has been commissioned in BARC and production trials with a few tons of $\mathrm{UO}_{2}$ pellets have been successfully completed. The facility essentially consists of:

(a) a train of interconnected glove boxes for preparation of MOx granules starting from $\mathrm{UO}_{2}$ and $\mathrm{PuO}_{2}$ powders by milling, blending, precompaction and granulation; (b) a compaction-sintering train consisting of a 30 ton automatic double action hydraulic press, dewaxing furnaces and a continuous sintering furnace (Sengupta et al 1982) (figure 25);

(c) a centreless grinder for grinding pellet to final diameter;

(d) a welding train for vacuum degassing of sintered pellets, followed by loading of pellets in a one end welded preautoclaved $4 \mathrm{~m}$ long zircaloy- 2 tubes and encapsulation by TIG welding under a helium pressure of around $0.3 \mathrm{MPa}$;

(e) a train of glove boxes for refabrication of sintered Mox pellets from rejected oxide; and

(f) facilities for nondestructive testing (NDT) of zircaloy hardwares and fuel pins by airgauging, ultrasonic testing, radiography, helium leak detection mass spectrometry and other quality control facilities like metallography, $x$-ray diffractometry and $\mathrm{x}$-ray fluorescence spectrometry.

The mechanical and thermal properties of $\mathrm{UO}_{2}$ are not significantly affected by addition of up to $5 \mathrm{w} / \mathrm{o}$ of $\mathrm{PuO}_{2}$. With $5 \% \mathrm{PuO}_{2}$ addition, the thermal conductivity is reduced by around $5 \%$, the melting point decreases by $26^{\circ} \mathrm{C}$, the thermal expansion and density increase marginally by $1 \%$, the fission gas release and swelling are unaffected and the creep and nuclear self-shielding properties are improved.

Irradiation-testing of a prototype MOx fuel cluster of 6 pins (figure 26) in the PWL, CIRUS was started in December 1979 simulating the operating conditions at TAPS. This MOX fuel cluster has performed very satisfactorily without failure up to the target burnup of $18000 \mathrm{MwD} /$ ton. A second similar cluster has already been fabricated and is under testing in the reactor.

\section{Mixed carbide and nitride fuels}

The mixed oxide fuels are not, however, the ultimate in the field of development of plutonium fuels for LMFBR. The oxide fuel has the inherent drawback of relatively low heavy atom density, high light atom fraction and poor thermal conductivity. These factors are responsible for its low breeding ratio and low power ratings. On the other hand the potential of (UPu)C and (UPu)N have all along been recognised as better and advanced LMFBR fuels on the basis of their higher breeding ratio and higher linear and specific power ratings which results in much shorter doubling time. An added advantage is the relatively good compatibility of (UPu)C and (UPu)N with sodium (Sengupta et al 1982). 

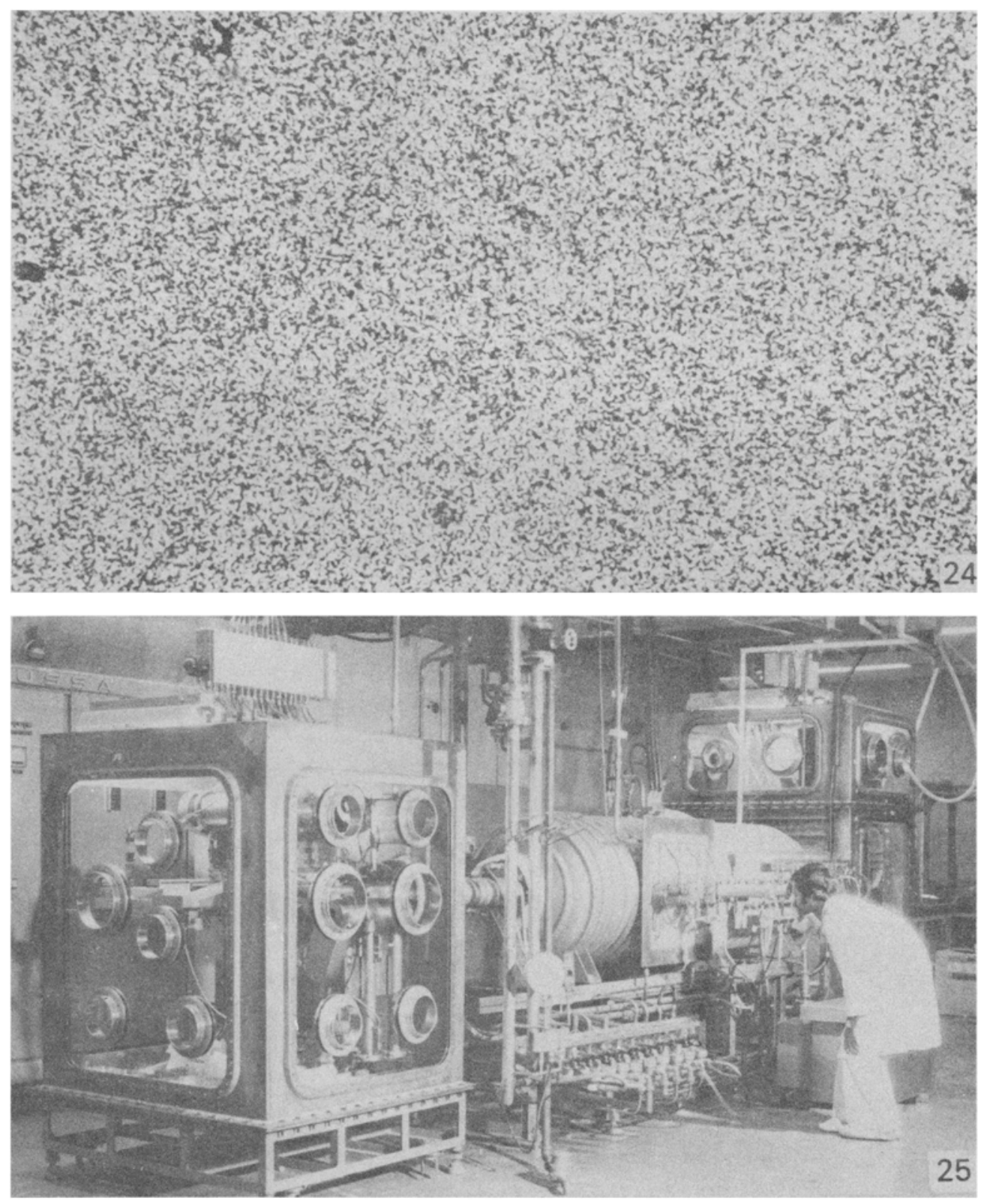

Figures 24, 25. 24. Alpha auto radiograph of mox pellets $(\times 80)$. 25. Continuous sintering urnace for Mox pellets.

Since piutomunin-rich mixed oxide fuels were not suitable for FBTR, efforts were directed to develop the fabrication flowsheet for plutonium rich (UPu)C and (UPu) $\mathrm{N}$ iuels. Towards the end of $1970 \mathrm{~s}\left(\mathrm{U}_{0.3} \mathrm{Pu}_{0.7}\right) \mathrm{C}$ and $\left(\mathrm{U}_{0.3} \mathrm{Pu}_{0.7}\right) \mathrm{N}$ pellets of controlled density and phase content were successfully produced in the plutonium metallurgy laboratory at Trombay as per the flowsheet shown in figure 27 (Ganguly 1980). 

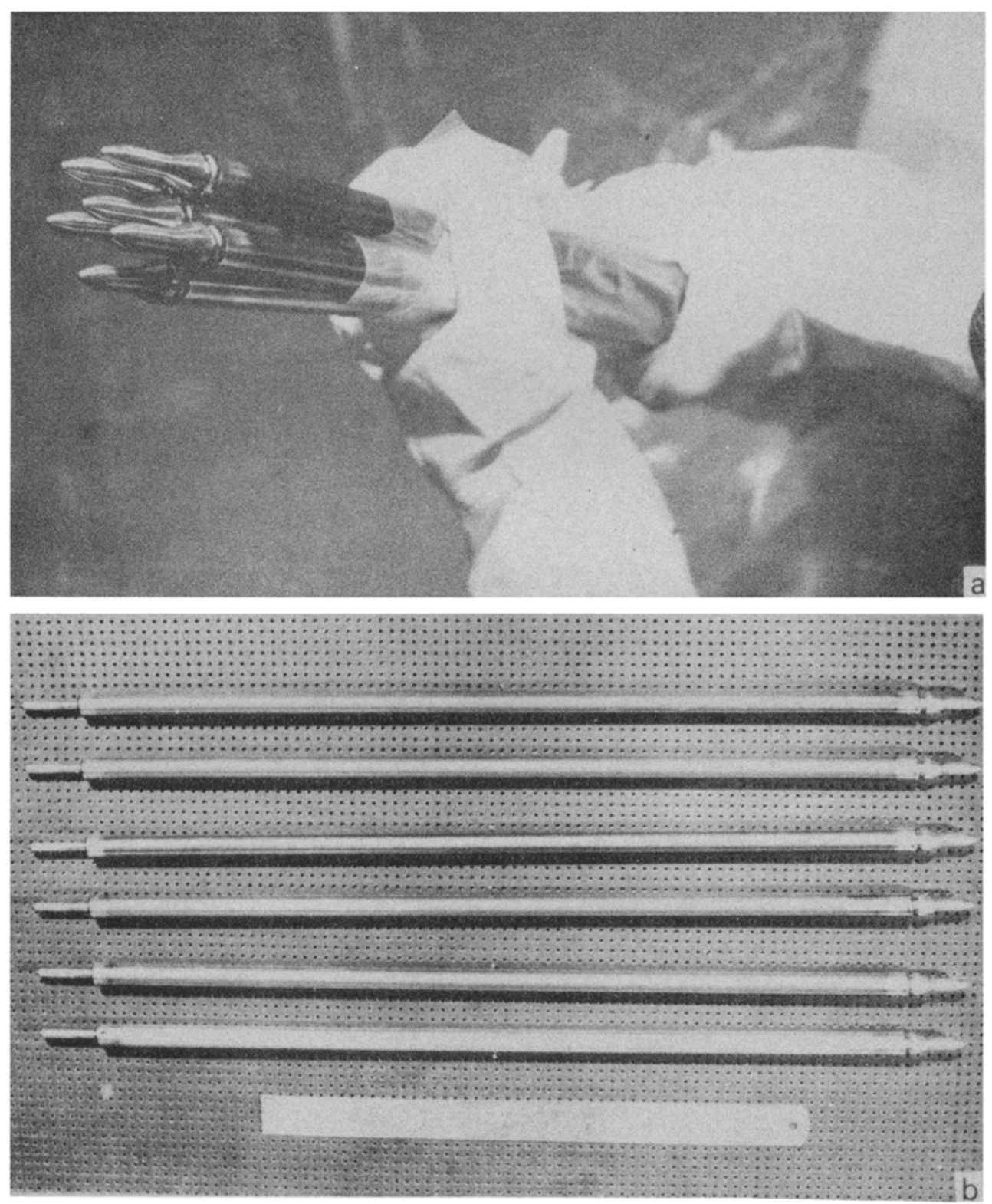

Figure 26. MOX fuel pin cluster for irradiation in PWL, CIRUs (a). MOX cluster (b). Individual Mox pins.

The two main stages in the fabrication are: (a) synthesis of (UPu)C and (UPu)N by carbothermic reduction of mechanically mixed $\mathrm{UO}_{2}, \mathrm{PuO}_{2}$ and graphite powders compacted in the form of tablets in vacuum or flowing argon for the carbide and flowing nitrogen or nitrogen $+8 \%$ hydrogen mixture for the nitride; (b) crushing and milling of carbide and nitride clinkers followed by cold pressing and sintering in argon, argon $+8 \%$ hydrogen or vacuum. 


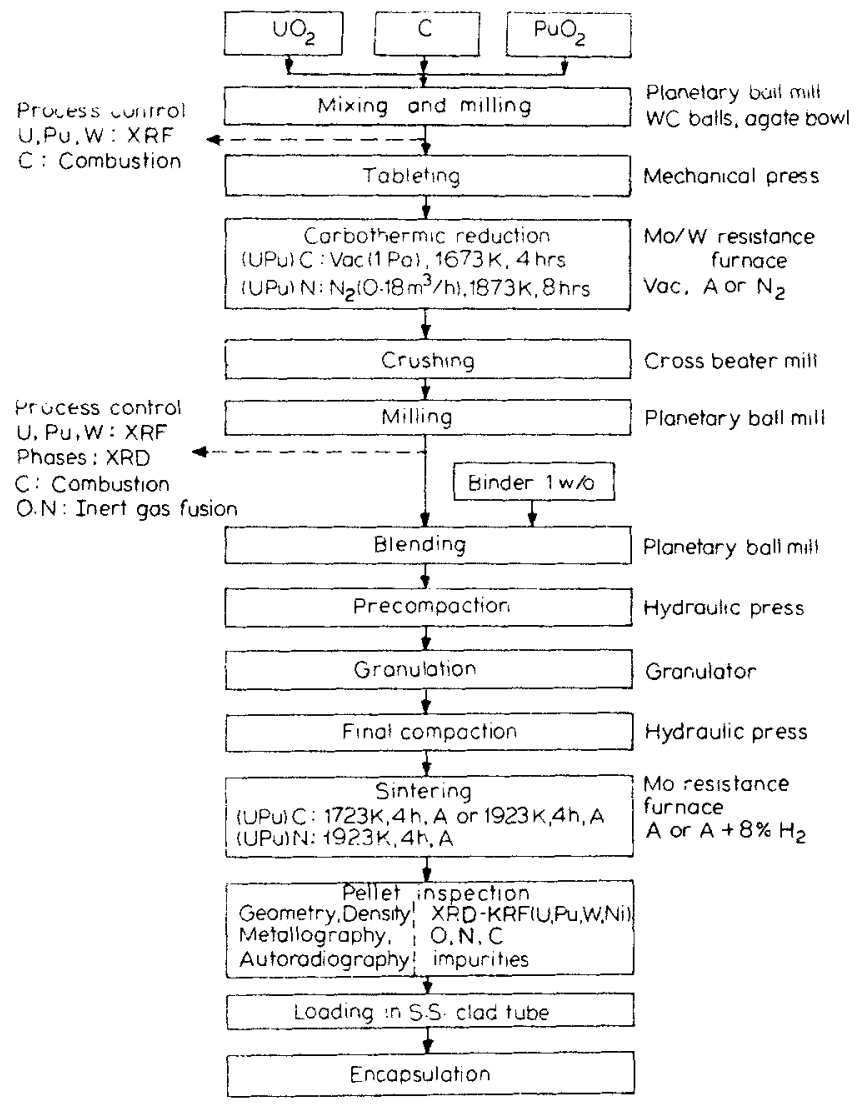

Figure 27. Flow sheet for preparation of $\left(\mathrm{U}_{0.3} \mathrm{Pu}_{0.7}\right) \mathrm{C}$ and $\left(\mathrm{U}_{0.3} \mathrm{Pu}_{0.7}\right) \mathrm{N}$ fuel pellets for LMFBR at BARC.

Equilibrium thermodynamic calculations confirmed by experimental results show that (UPu)C prepared by carbothermic reduction of oxides contain substantial amount of oxygen because of the formation of a mixed uranium plutonium monoxy-carbide solid solution in the final stage of the carbothermic reduction process which above $1625^{\circ} \mathrm{C}$ remove essentially all the oxygen from the monocarbide but might result in the formation of the undesirable liquid phase $\mathrm{PuC}_{1-x}$ by peritectic decomposition and lead to high plutonium volatilisation losses.

In the synthesis of (UPu) $\mathrm{N}$ by solid state carbothermic reduction of a powder mixture of $\mathrm{UO}_{2}, \mathrm{PuO}_{2}$ and graphite, nitrogen plays the dual role of the reactant and the carrier for the removal of $\mathrm{CO}$. The (UPu)N produced by this method has high oxygen and carbon contents.

\subsection{Advantages of plutonium rich $(U P u) C$ and $(U P u) N$}

Initial theoretical studies on plutonium rich (UPu)C and (UPu)N unfolded the following advantages of this fuel over the uranium rich composition: (a) UC and uranium rich (UPu)C have no carbon solubility range but there is a limited carbon homogeneity range in the $\mathrm{PuC}$ and plutonium rich $(\mathrm{UPu}) \mathrm{C}$ as shown in the $\mathrm{U}-\mathrm{Pu}-\mathrm{C}$ 
phase diagram (figure 28) (Storms and Ackermann 1974). It is, therefore, relatively simple to prepare $\left(\mathrm{U}_{0.3} \mathrm{Pu}_{0.7}\right) \mathrm{C}$ as a nearly single phase material.

(b) With nitrogen, plutonium forms only one compound namely $\mathrm{PuN}$ whereas uranium has three nitrogen compounds, namely $U N, U_{2} N_{3}$ and $U_{2}$ (Potter 1975). The higher nitrides of uranium, however, are easily decomposed to the mononitride by a high temperature treatment in vacuum or inert gas. Single phase PuN and plutonium rich $(\mathrm{UPu}) \mathrm{N}$ are therefore relatively easy to prepare.

(c) $\mathrm{Pu}_{2} \mathrm{C}_{3}$ and $\left(\mathrm{U}_{0.3} \mathrm{Pu}_{0.7}\right) \mathrm{C}_{1.02}$ have lower carbon potentials compared to $\mathrm{U}_{2} \mathrm{C}_{3}$ at all temperatures and a lower carbon potential than stainless steel 316 up to $725^{\circ} \mathrm{C}$ as shown in figure 29 (Gotzmann and Hofmann 1974; Internal report 1980). The chances of carbon transfer from plutonium rich mixed carbide to stainless steel is therefore lower and there will be no clad carburisation if the temperature inside the clad is kept below $725^{\circ} \mathrm{C}$.

(d) The melting points of (Sheth and Leibonitz 1974) of PuC and PuN are less than that of UC and UN respectively for which the optimum carbothermic and sintering temperatures of plutonium rich (UPu)C and (UPu) $\mathrm{N}$ are $150-200^{\circ} \mathrm{C}$ lower than their uranium rich counterparts (Ganguly et al 1980, 1982). Hence, the plutonium volatilisation losses are relatively less (within 1--2\%).

\subsection{Mixed carbide facility for FBTR}

The small scale $(60 \mathrm{~g})$ laboratory experiments established the overall feasibility of the fabrication of controlled density $(\mathrm{UPu}) \mathrm{C}$ and $(\mathrm{UPu}) \mathrm{N}$ pellets as nearly single phase material as shown in the $\mathrm{x}$-ray diffraction patterns (figure 30 ) and the microstructures (figure 31). On the basis of this experience a production laboratory was set up during 1981-82 for the fabrication and quality control of $1.5 \mathrm{~kg} /$ day of finished mixed carbide fuel pellets from $\mathrm{UO}_{2}$ and $\mathrm{PuO}_{2}$ feed materials (Ganguly and Roy 1981). This laboratory has two main facilities, namely (a) pellet production facility, and (b) process control facility.

The pellet production facility consists of a train of 12 interconnected glove boxes housing conventional powder metallurgy equipment. In addition, for rapid process control at different stages in the preparation and sintering of $\mathrm{MC}$ and $\mathrm{MN}$

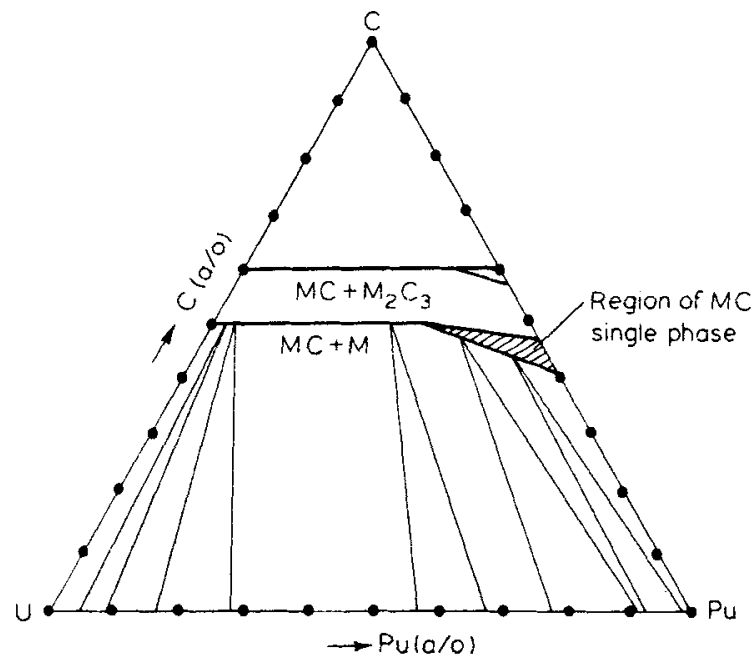

Figure 28. U-Pu-C system at $600^{\circ} \mathrm{C}(\mathrm{M}=\mathrm{U}, \mathrm{Pu})$. 


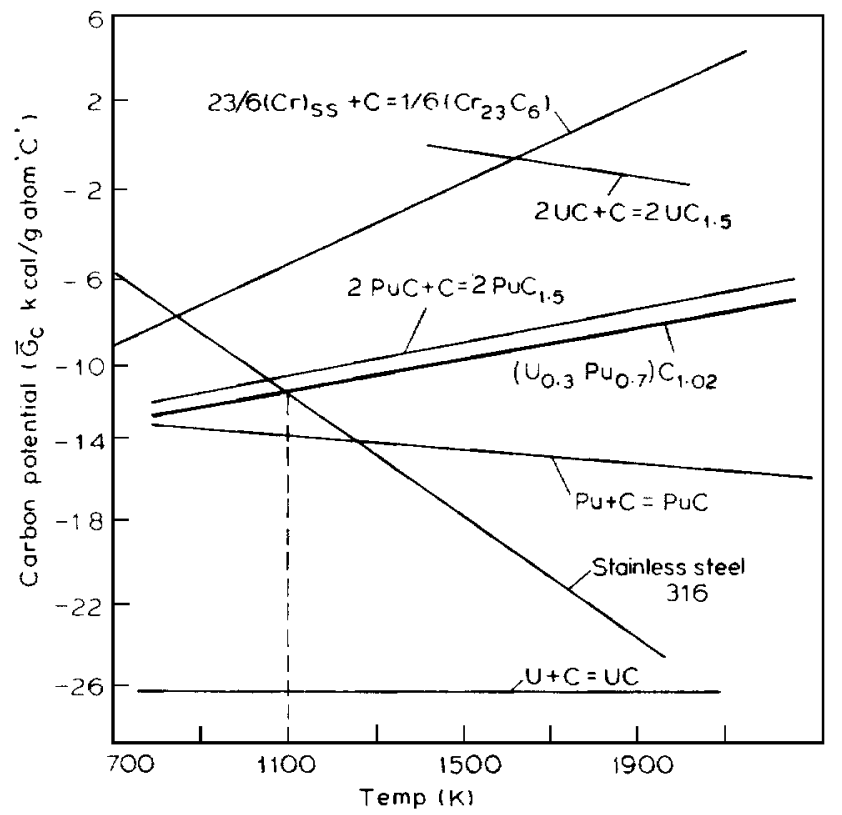

Figure 29. Carbon potentials of carbides.

(a)

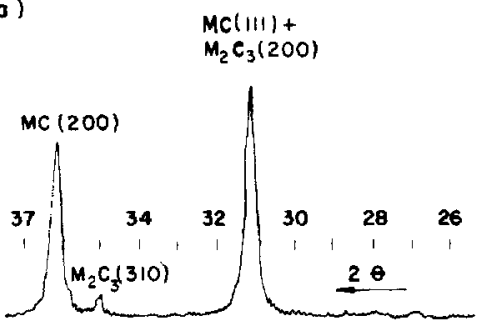

(c)

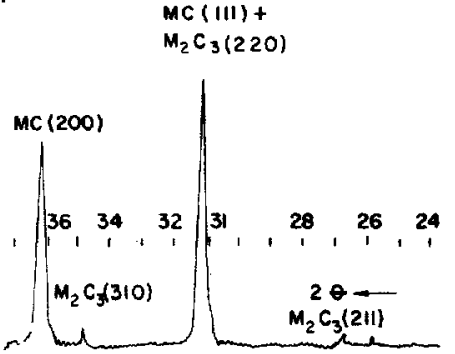

(b)

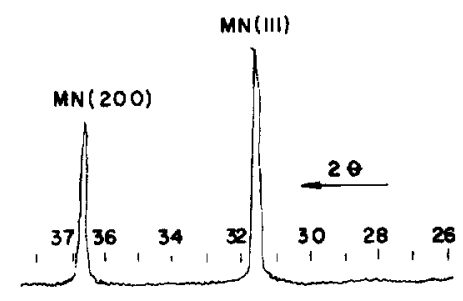

(d)

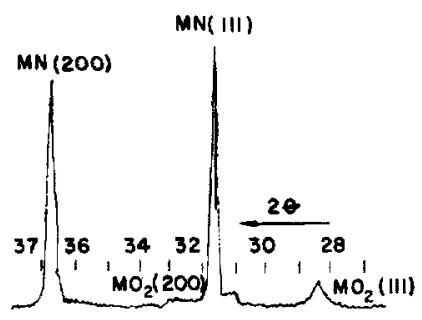

Figure 30. X-ray diffraction pattern of $\mathrm{MC}$ and $\mathrm{MN} ; \mathrm{M}=\left(\mathrm{U}_{0.3} \mathrm{Pu}_{0.7}\right)$ after carbothermic reduction of $\mathrm{UO}_{2}+\mathrm{PuO}_{2}+\mathrm{C}$ for (a). carbide (b). nitride; after sintering of (c). carbide (without $-\mathrm{Ni}$ ) and (d). nitride. 
powders the following equipment have also been installed (Ganguly et al 1981): (a) a combined and sequential oxygen and nitrogen inert gas fusion analyser for rapid analysis of oxygen and nitrogen in powders and pellets; (b) a rapid carbon analyser for powder and pellet based on the method of combustion and determination by thermal conductivity meter; (c) an automatic, combined and sequential x-ray fluorescence spectrometer and $\mathrm{x}$-ray diffractometer for rapid analysis of $\mathrm{U}, \mathrm{Pu}$, tungsten, nickel and different phases present in powder and pellets (figure 32).
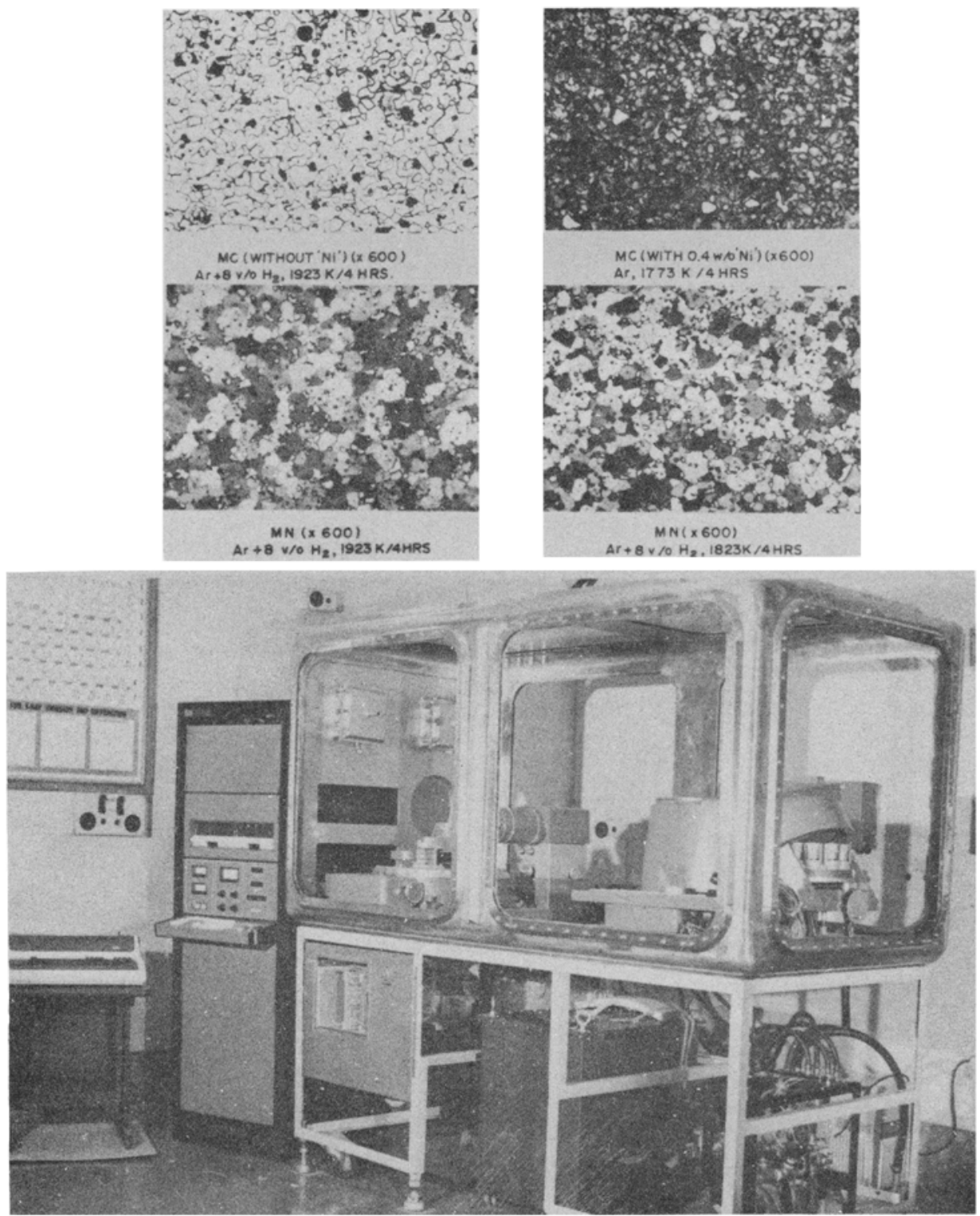

Figures 31, 32. 31. Microstructure of plutonium rich $(\mathrm{UPu}) \mathrm{C}$ and (UPu)N pellets 32. Combined XRD-XRF unit in RMD, BARC under commissioning inside a glove box. 


\section{Looking forward}

In our travels into the plutonium age over the past quarter or a sentury, we have passed many milestones, meeting new challenges, probing new frontiers, indigenising all aspects of plutonium metallurgy and fuels and have reached today a stage of commercial exploitation of plutonium in nuclear power reactors.

Our well-known three stage nuclear power strategy projects the pivotal role of plutonium in the coming decades for a viable and rapidly expanding electricity generation programme. The first stage based on our operating and forthcoming natural $\mathrm{UO}_{2}$ fuelled PHWRs will be limited to only $10-15 \mathrm{GW}(\mathrm{e})$ for $30 \mathrm{yr}$ but will produce between 100-150 tons of fissile plutonium as by-product along with depleted uranium. The second stage, which is likely to start towards the turn of this century, will make most effective utilisation of these large quantities of plutonium by recycling it several times with depleted uranium in LMFBR. Around $350 \mathrm{GW}(\mathrm{e})$ would be possible for $65 \mathrm{yr}$ with ${ }^{238} \mathrm{U}-{ }^{239} \mathrm{Pu}$ fuel cycle and simultaneously ${ }^{232} \mathrm{Th}$ could be converted to ${ }^{233} \mathrm{U}$. Finally, in the third stage, the self sustaining ${ }^{232} \mathrm{Th}^{-2}{ }^{23} \mathrm{U}$ thermal breeder fuel cycle could be used in PHWR to unlock $1000 \mathrm{GW}$ (e) for $240 \mathrm{yr}$, thus establishing that nuclear power is the only long term answer to our energy crisis.

A plutonium-fuelled prototype fast breeder reactor of $500 \mathrm{MW}(\mathrm{e})$ capacity (PFBR-500) has been already planned for the 1990s (Singh et al 1981). This reactor will essentially act as a "lead station" to demonstrate the basic safety, reliability and economics of plutonium fuel reprocessing, refabrication and irradiation on a commercial scale and will generate data on which "series ordered LMFBR stations" can be commissioned with confidence after 2010 .

A larger capacity plutonium fuel fabrication plant is coming up at Tarapur to meet our future requirement of plutonium fuels in PFBR -500 and thermal reactors. This plant is being designed and constructed in the philosophy of "secured automated fabrication (SAF)" through a carefully staged development from present glove box operations to semi-remote or remote operations placing emphasis on radiotoxic dust reduction and its containment. This development should ultimately result in systems that maximise personnel radiation protection, restrict and control access to plutonium, provide near real time accountability and improve the uniformity and quality of plutonium fuels.

New fabrication flowsheets for plutonium bearing fuels amenable to automation and remotisation are being developed in Trombay. One of the promising process is the 'gelpelletisation route' (Gilissen et al 1982) which uses gel derived microspheres rather than powder as feed material for pellet pressing. Because of the free flowing and dust-free nature of microspheres, the gel-pelletisation process is ideally suited for remote fabrication of the fuel pellets. In our preliminary experiments with gelled microspheres of $(\mathrm{UPu}) \mathrm{O}_{2}$, high density sintered pellets have been prepared. Figure 33 shows the microstructure of such a pellet and figure 34 shows the alpha autoradiograph.

The $\mathrm{ThO}_{2}-\mathrm{PuO}_{2}$ (up to maximum of $5 \% \mathrm{PuO}_{2}$ ) is a promising fuel for our thorium based PHWR (Ganguly and Roy 1982). If due to technological or political reasons recycling of plutonium is delayed in our LMFBR, such fuels could be conveniently used in our existing PHWR without involving major resource investment and engineering modifications.

In conclusion it may be stated that plutonium technology is mostly classified in nature and detailed informations are not available in open literature. In spite of that we have succeeded in the harnessing of plutonium entirely with indigenous resources and 

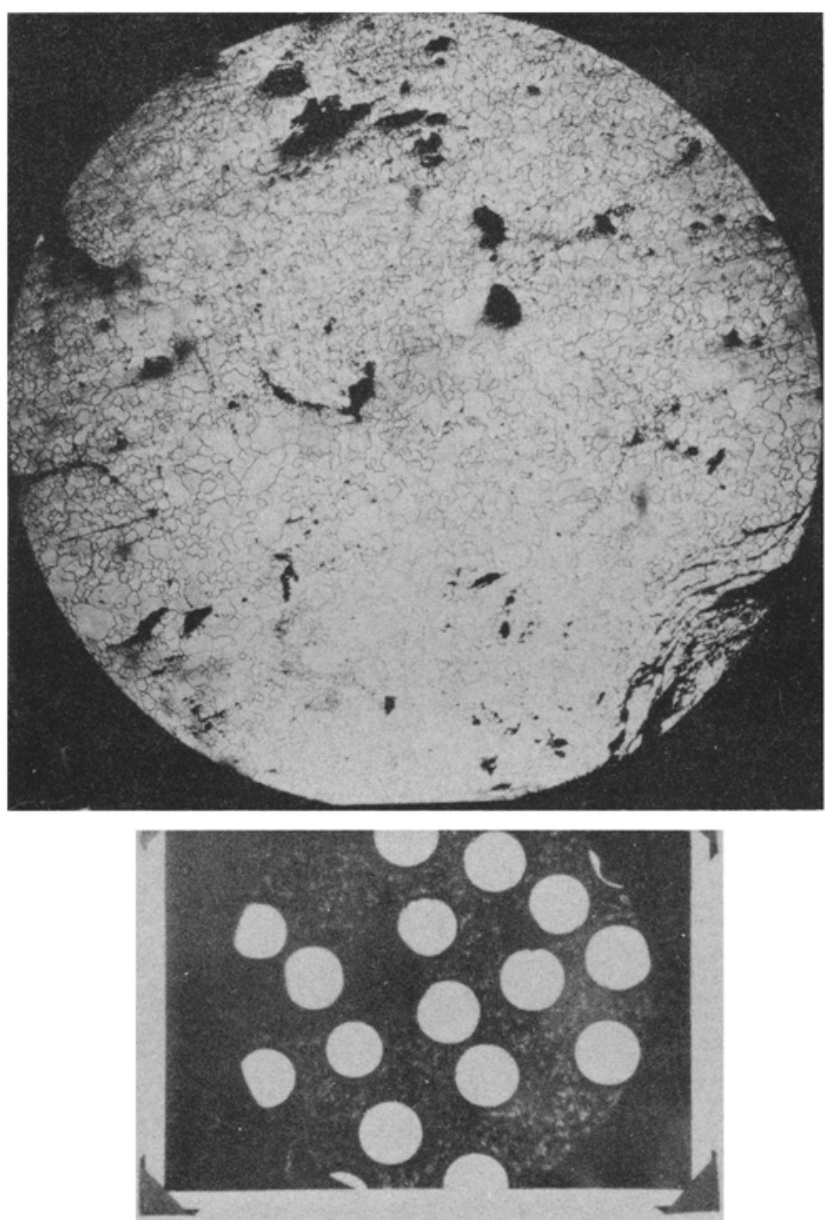

PHOTOMICROGRAPH Mag: 20X

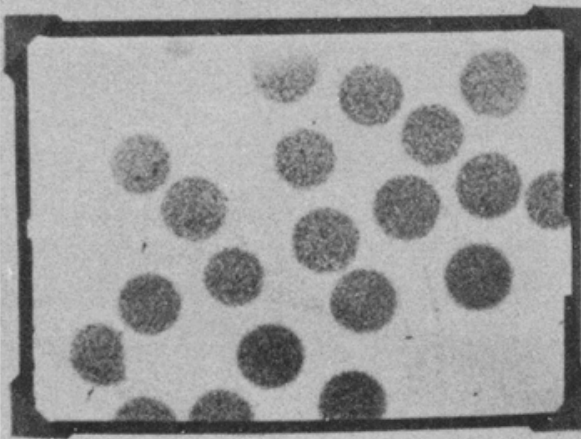

AUTORADIOGRAPH Mag:20X

Figures 33, 34. 33. Microstructure of $\mathrm{UO}_{2}$ pellet prepared by the gel pelletisation route $(\times 90)$. 34. Microstructure and alpha-autoradiograph of mox structures. 
without any foreign assistance. Only a vertucal take off is needed and a few obstacles are to be overcome before this great gift of nature and our control over it bears the fruit of its present promise.

\section{Acknowledgement}

Thanks are due to the Radiometallurgy Division as a whole, including the staff members of Post Irradiation Examination, Engineering Services, Oxide Fuels, Advanced Fuels, Quality Control and Inspection and Cladding and Welding Sections. In addition, the support from Fuel Reprocessing Division and Radiochemistry Division is acknowledged. The continuous encouragement received from the higher authorities is also gratefully acknowledged.

\section{References}

Coffinberry A S and Miner W N 1961 The metal plutonium (Chicago: University Press)

Ellinger F G, Land C C and Miner W N 1962 J. Nucl. Mater. 5165

Fareeduddin S, Garg R K, Gupta U C, Kantan S K, Rajendran R and Rao N K 1964 3rd Int. Conf. Peaceful use of atomic energy, IAEA, Vol. II p 345

Ganguly $\mathrm{C} 1980$ Studies on preparation and sintering of mixed uranium plutonium monocarbide, mononitride and monocarbonitride; Ph.D. Thesis, University of Calcutta

Ganguly C, Jain G C and Roy P R 1981 Proc. of DAE Sym. on Nucl. Chemistry and Radiochemistry

Ganguly C and Roy P R 1981 Proc. BNES Conf. on Fast Reactor Fuel Cycles, London

Ganguly C and Roy P R 1982 Proc. Int. Sym. in Ceramics, BHEL Bangalore

Ganguly C, Roy P R and Seal A K 1980 Trans. PMAI 740

Ganguly C, Roy P R and Seal A K 1982 Trans. IIM Vol. 35 No. 2 p 148

Ghosh J K, Roy P R and Moorthy V K 1973 BARC/1-254

Gilissen R, Panwels H, Sleurs J and Smolders A 1982 Trans. Am. Nucl. Soc. 4026

Gotzmann O and Hofmann P 1974 Proc. of Int. Sym. on Fuel and Fuel Elements for Fast Reactor IAEA p 233

Hanna G C, Westcott C H, Lemmel H D, Leonard B R Jr., Story J S and Altree P M 1969 Atomic Energy Rev. 7 p. 3

Hansen L P and Clayton R D 1967 Nucl. Appl. 3484

Housseau M 1974 Proc. Sym. on fuel and fuel element for fast reactors, IAEA p 277

Internal Report prepared on FBTR mixed oxide fuel by DAE, India and CEA, France (Sept. 1970)

Internal Report of DAE working group on mixed uranium plutonium carbide fuels for FBTR (1980)

Janardhanan S, Krishnamurthi T N, Dabhadkat S B and Soman S D 1973 BARC/I-259

Kanij J B W, Noothont A J and Votock I 1974 IAEA-161 p 185, Vienna

Mahajan V K, Ganguly C, Ramakumar M S, Roy P R and Moorthy V K 1972 BARC-629

Majumdar S, Arunkumar, Kamath H S, Ramachandran R, Purushotham D S C and Roy P R 1984 BARC1182

Majumdar S, Purushotham D S C and Roy P R 1982 BARC/I-730

Potter P E 1975 Plutonium and other actinides p 211

Prasad G J, Ganguly C and Roy P R 1976 BARC/I-423

Recommendation of the ICRP-Suppl. 6, $1955 \mathrm{Br}$. J. Radiol.

Ramachandran R, Arunkumar, Purushotham D S C and Roy P R 1981 Trans. PMAI 8277

Rao N K 1982 Proc. Sym. Int. Conf. on Nucl. Power Experience IAEA, Vienna

Roy P R 1962 AEET/Radiochem. 22

Roy P R 1964 J. Nucl. Mater. 1159

Roy P R 1975 Proc. IAEA group meeting on facilities and techniques for $(U \mathrm{Pu}) \mathrm{O}_{2}$ fuel fabrication, Mol, Belgium

Roy P R 1978 Proc. Seminar on Nucl. Metallurgy, IIM Bombay

Roy P R, Deshpande R G and Laxminarayanan T S 1967 BARC-294

Roy P R, Laxminarayanan T S, Singh R K and Haraprakash A 1969 BARC/1-37 
Roy P R and Mahajan V K 1975 Proc. IWSA-BARC Winter School, Bombay

Roy P R, Purushotham D S C, Majumdar S, Ramachandran R, Kamath H S, Ghosh J K and Goswami G L et al 1984 BARC-1203

Sah D N, Sahoo K C, Chatterjee S, Majumdar S, Kamath H S, Ramachandran R, Bahl J K, Purushotham D S C, Ramakumar M S, Sivaramakrishnan K S and Roy P R 1977 BARC-918

Seaborg G T 1958 The transuranium elements (Massachusetts, USA: Addison-Wesley Publishing Co.)

Sengupta A K, Ganguly C and Roy P R 1982 BARC/I-740

Sheth A and Leibonitz L 1974 ANL-AFP-3

Singh B, Bhoje S B, John T M, Lee S M, Singh R S and Paranjpe S R 1981 Proc. BNES Conf. on Fast Reactor Fuel Cycles, London

Sood D D and Vaidya V N 1979 Proc. Sym. on Sintering and Sintered Products, BARC, Bombay

Stoller S M and Richards R B 1961 Reactor Handbook (New York: Interscience Publishers) 2454

Storms E K and Ackermann R J 1974 Proc. of IAEA Panel Meeting on U-Pu-C System, Grenoble, France Wade W Z and Wolf T 1969 J. Nucl. Sci. Technol. 6402

Wick O J 1980 Plutonium handbook (La-Crange Park, Illinois: American Nuclear Society)

Zachariasen W H and Ellinger F H 1959 Acta Crystallogr. 12175 